\title{
Energy-transfer-induced multi-excitation and enhanced emission of hyperbranched polysiloxane
}

Lihua Bai, ${ }^{a}$ Hongxia Yan, ${ }^{*, a}$ Tian Bai, ${ }^{a}$ Liulong Guo, ${ }^{a}$ Tingli Lu ${ }^{b}$, Yan Zhao, ${ }^{*, a}$ Chujia $\mathrm{Li}^{\mathrm{c}}$

a Key Laboratory of Polymer Science and Technology, Shaanxi Province, School of Science, Northwestern Polytechnical University, Xi'an 710129, China.

b Key Laboratory for Space Biosciences \& Biotechnology, Faculty of Life Science, Northwestern Polytechnical University, Xi'an 710072, China.

c Queen Mary University of London Engineering School, Northwestern Polytechnical University, Xi'an 710072, Shaanxi Province, China

*Corresponding author. E-mail address: hongxiayan@nwpu.edu.cn; zhaoyan@nwpu.edu.cn

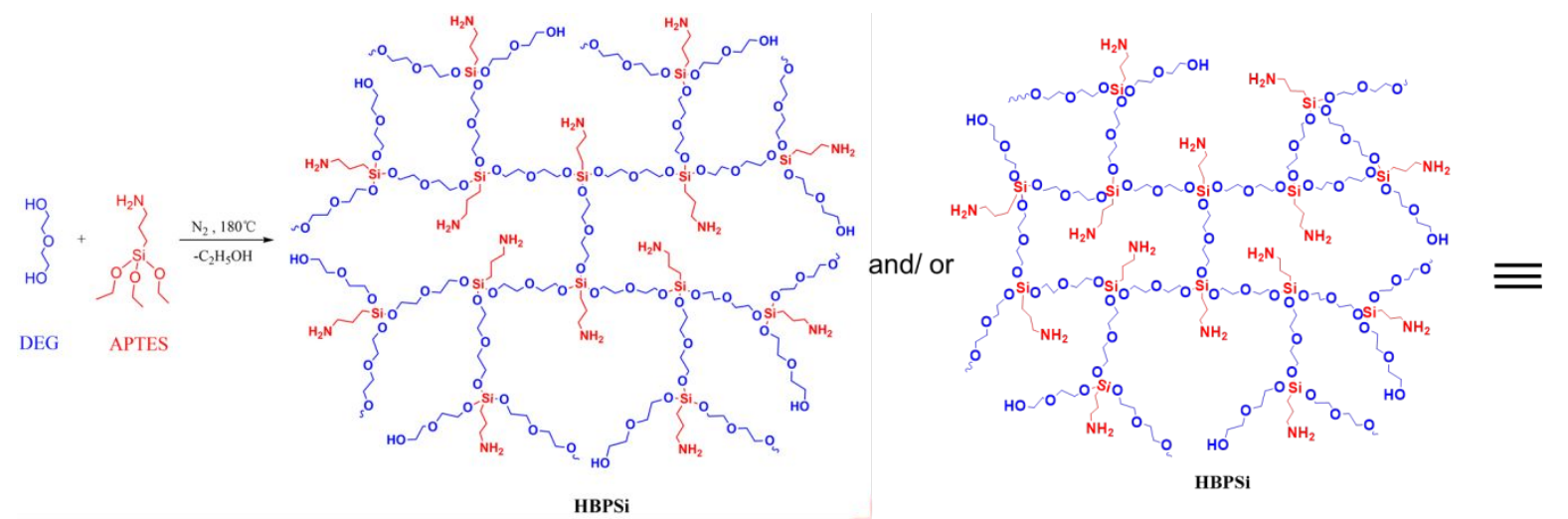

Scheme S1. The synthesis route of HBPSi and HBPSi-GA with crosslinking structure. 

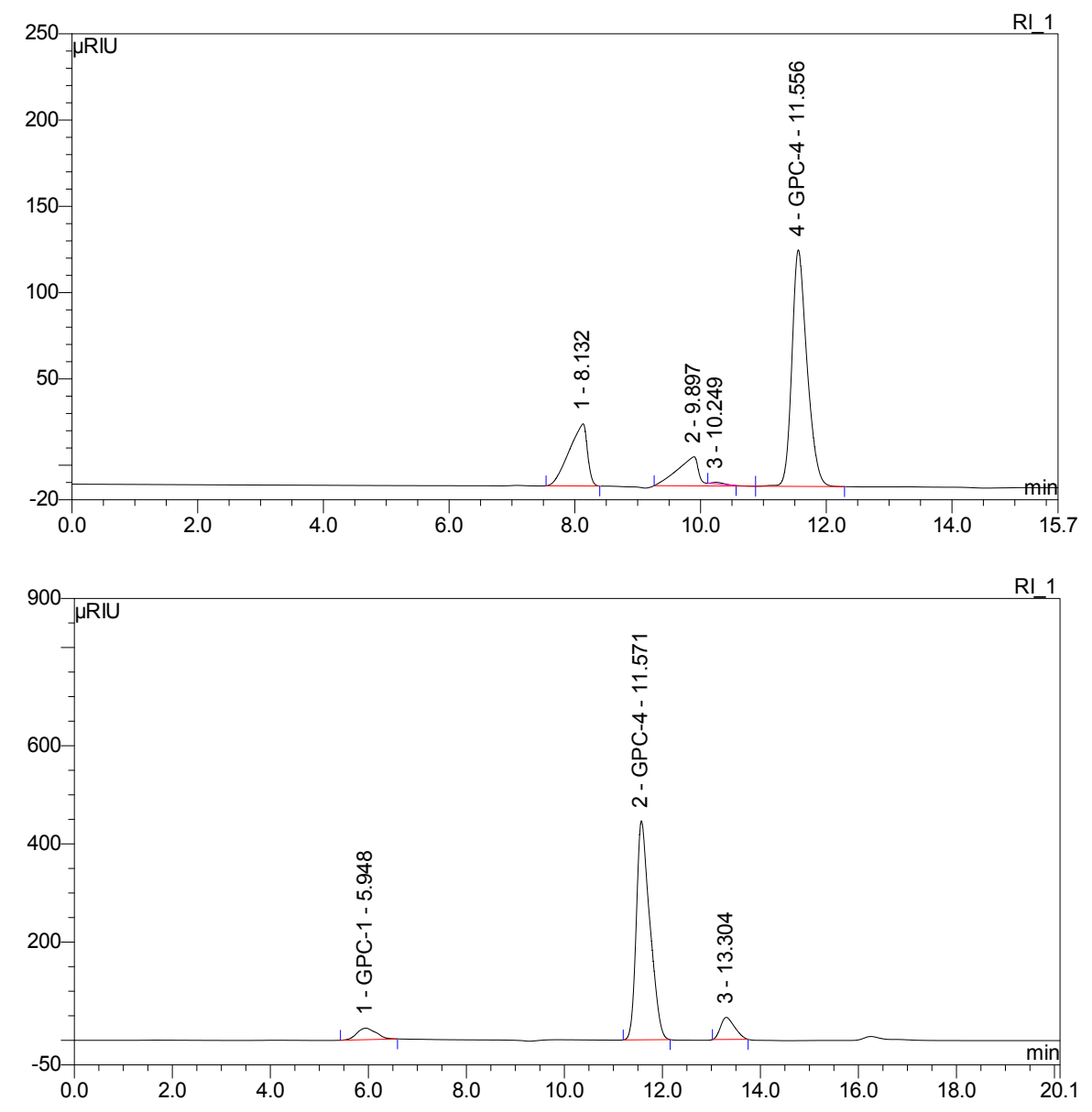

Figure S1. GPC curves of HBPSi and HBPSi-GA3 (from top to down).

Figure S1 shows the GPC curves of HBPSi and HBPSi-GA3. In the GPC curve of HBPSi, peak 1 shows that the average molecular weight $\left(M_{\mathrm{w}}\right)$ and number average weight $\left(M_{\mathrm{n}}\right)$ are 5997 and $3776 \mathrm{~g} \mathrm{~mol}^{-1}$, thus the polydispersity index (PDI) is 1.59. Peak 2 shows that the $M_{\mathrm{w}}$ is 960 $\mathrm{g} \mathrm{mol}^{-1}$, which is very close to the cut-off of the dialysis bag (1000 Da), thus some HBPSi with small molecular weight still exist after dialysis. However, compared with peak 1, the area of peak 2 is much lower. In the GPC curve of HBPSi-GA3, peak 1 shows that the $M_{\mathrm{w}}$ and $M_{\mathrm{n}}$ are 9255 and $6921 \mathrm{~g} \mathrm{~mol}^{-1}$, respectively, and thus its polydispersity index (PDI) is 1.34. The molecular weight of peak 2 is between 19-158, which might be caused by the existed by-product (ethanol). Furthermore, most HBPSi with low molecular weight is removed through the second dialysis after L-glutamic acid is introduced. Compared with HBPSi, the main molecular weight of HBPSi-GA3 is much higher. Thus, the GPC results demonstrate that HBPSi and HBPSiGA3 are successfully synthesized. The detail information of the molecular weight of HBPSi and HBPSi-GA3 has been listed in Table S1. 
Table S1. Reaction Conditions and characterization data of the resultant polymers

\begin{tabular}{lllllll}
\hline Sample & HBPSi (g) & GA $(\mathrm{g})$ & GA content $(\%)^{\mathrm{a}}$ & $M_{\mathrm{w}} \mathrm{b}$ & $M_{\mathrm{n}}^{\mathrm{b}}$ & $M_{\mathrm{w}} / M_{\mathrm{n}}^{\mathrm{b}}$ \\
\hline HBPSi & 10.00 & 0.00 & 0 & 5997 & 3776 & 1.59 \\
HBPSi-GA1 & 10.00 & 0.50 & $4.76 \%$ & - & - & - \\
HBPSi-GA2 & 10.00 & 1.00 & $9.09 \%$ & - & - & - \\
HBPSi-GA3 & 10.00 & 1.50 & $13.04 \%$ & 9255 & 6921 & 1.34 \\
${ }^{\mathrm{a}}$ Content of GA in the resultant polymers was calculated by $m_{\mathrm{GA}} /\left(m_{\mathrm{GA}}+m_{\mathrm{HBPSi}}\right) .{ }^{\mathrm{b}}$ Molecular weights were \\
\multicolumn{7}{l}{ determined by an ultimate 3000 UHPLC System. }
\end{tabular}

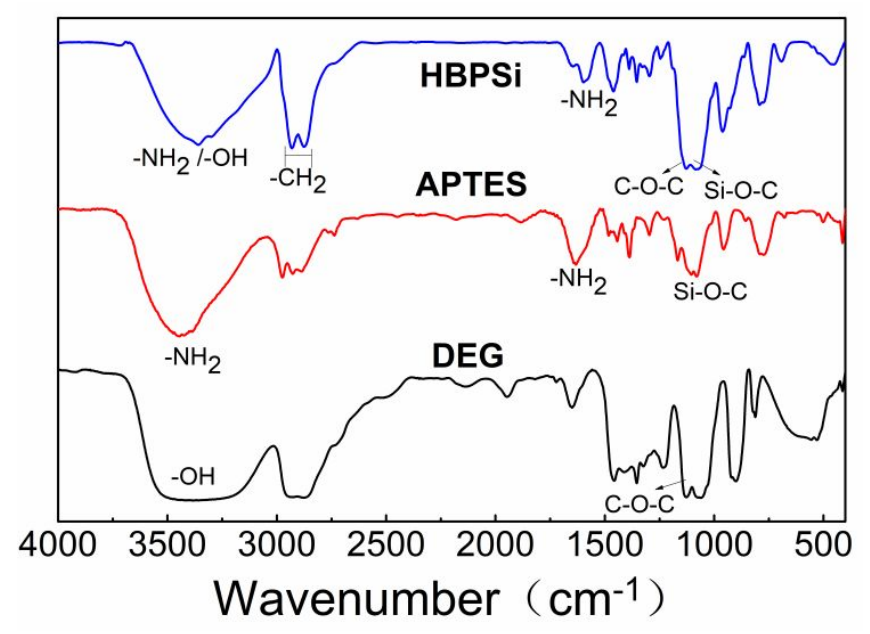

Figure S2. FTIR spectra of DEG, APTES and HBPSi.

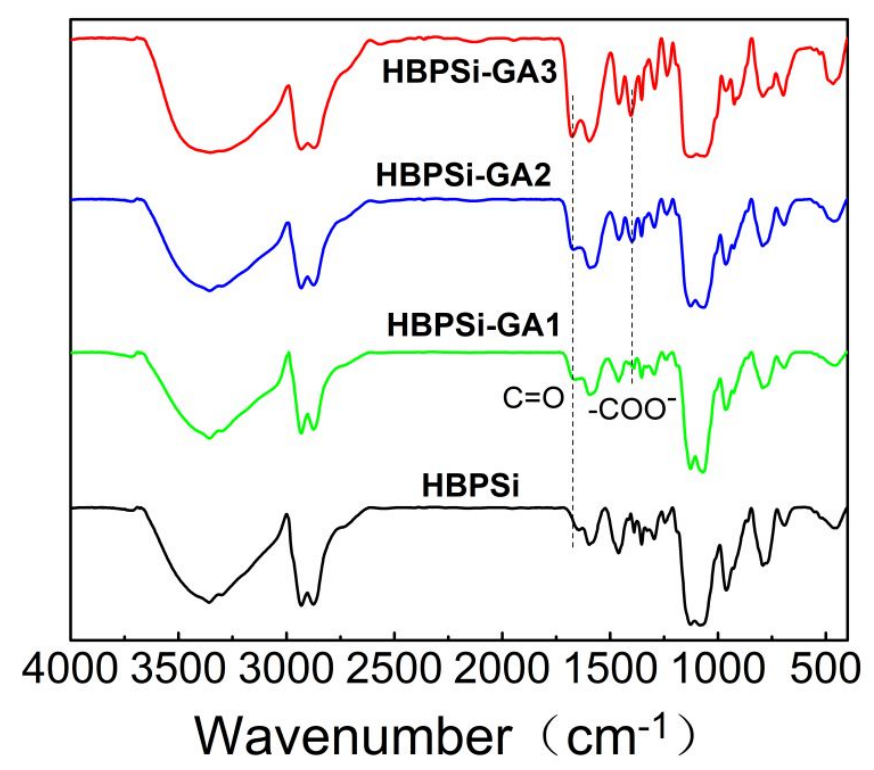

Figure S3. FTIR of HBPSi and HBPSi-GA. 
In the FTIR spectrum of DEG (Figure S2), the absorption peaks at 3458 and $1123 \mathrm{~cm}^{-1}$ belong to the stretching vibration of $-\mathrm{OH}$ and $\mathrm{C}-\mathrm{O}-\mathrm{C}$. In the absorption spectrum of APTES, peaks at 3425,1081 and $1626 \mathrm{~cm}^{-1}$ are attributed to the stretching vibration of $-\mathrm{NH}_{2}, \mathrm{Si}-\mathrm{O}-\mathrm{C}$ and the bending vibration of $-\mathrm{NH}_{2}$, respectively. In the FTIR spectrum of HBPSi, absorption peaks at 3360, 3296, 2934 and 2874, 1121 and $1081 \mathrm{~cm}^{-1}$ are ascribed to the stretching vibration of $-\mathrm{NH}_{2},-\mathrm{OH},-\mathrm{CH}_{2}-, \mathrm{C}-\mathrm{O}-\mathrm{C}$ and Si-O-C, separately. Peaks at 1647 and $1587 \mathrm{~cm}^{-1}$ are corresponded to the bending vibration of $-\mathrm{NH}_{2}$ in the HBPSi. These absorption peaks indicate that the HBPSi was successfully synthesized. The FTIR spectra of HBPSi-GA1, HBPSi-GA2 and HBPSi-GA3 (Figure S3) are quite similar to that of HBPSi, indicating that all polymers have the basic molecular structure. Meanwhile, new peaks at 1671 and $1400 \mathrm{~cm}^{-1}$ are observed in the spectra of HBPSi-GA, which are ascribed to the vibration of $\mathrm{C}=\mathrm{O}$ of imide and $-\mathrm{COOH}$, respectively. Furthermore, the peak intensities at 1671 and $1400 \mathrm{~cm}^{-1}$ are increased with increasing GA content. These newly appeared absorption peaks indicate that different amount of GA has been successfully grafted onto HBPSi.

${ }^{1} \mathrm{H}$ and ${ }^{13} \mathrm{C}$ NMR spectra were used to further confirm the structure of HBPSi and HBPSiGA. In the ${ }^{1} \mathrm{H}$ spectrum of HBPSi (Figure S4a), signals at 3.54, 2.49, 1.48-1.34 and 0.57 ppm come from protons of methylene groups $\left(-\underline{\mathrm{C}}_{2}-\right)$ of $\mathrm{Si}-\mathrm{O}-\underline{\mathrm{C}}_{2}-\mathrm{C}_{2}-\mathrm{O}$ and $\mathrm{Si}-\mathrm{O}-\mathrm{C}_{2}-\mathrm{CH}_{3}$, Si$\mathrm{CH}_{2}-\mathrm{CH}_{2}-\underline{\mathrm{C}}_{2}-\mathrm{NH}_{2}$, Si- $\mathrm{CH}_{2}-\underline{\mathrm{CH}}_{2}-\mathrm{CH}_{2}-\mathrm{NH}_{2}$ and $\mathrm{Si}-\mathrm{CH}_{2}-\mathrm{CH}_{2}-\mathrm{CH}_{2}-\mathrm{NH}_{2}$, respectively. The signals at 3.38 and $1.06 \mathrm{ppm}$ are attributed to the protons of $-\mathrm{OH}$ and $-\mathrm{N}_{2}$. Signal at $1.48-$ $1.34 \mathrm{ppm}$ comes from the proton of methyl group of $\mathrm{Si}-\mathrm{O}-\mathrm{CH}_{2}-\mathrm{CH}_{3}$. In the ${ }^{13} \mathrm{C}$ spectrum of HBPSi (Figure S4b), the signals of secondary carbons $\left(-\mathrm{CH}_{2}-\right)$ at $72.95,72.02,71.14,62.92$, $61.95,60.61,58.21,45.10,27.16$ and $8.97 \mathrm{ppm}$ are corresponded to $\mathrm{C} 10, \mathrm{C} 2, \mathrm{C} 3, \mathrm{C} 4, \mathrm{C} 1, \mathrm{C} 9$, C12, C7, C6 and C5, respectively. The signal at $18.33 \mathrm{ppm}$ is ascribed to primary carbon ($\mathrm{CH}_{3}$ ) of C13. ${ }^{1} \mathrm{H}$ and ${ }^{13} \mathrm{C}$ NMR signals further confirmed the successful synthesis of the HBPSi. After the modification of GA, four new signals at 7.43, 3.66, 2.13 and 2.03 ppm appear in the ${ }^{1} \mathrm{H}$ spectra, which correspond to the protons of GA (Figure S4c). In the ${ }^{13} \mathrm{C}$ spectrum of HBPSiGA3, five new signals are appeared at 181.65, 180.16, 55.49, 33.83 and 30.60 ppm, which corresponds to the carboxyl, imide, methylene and methine groups of GA (Figure S4d). Furthermore, the signals of the protons (H9 and H10) and secondary carbons (C8 and C12) of GA are enhanced with the increase of GA (Figure S5). Both the FTIR and the NMR results 
illustrate that different contents of GA have been successfully grafted onto HBPSi.
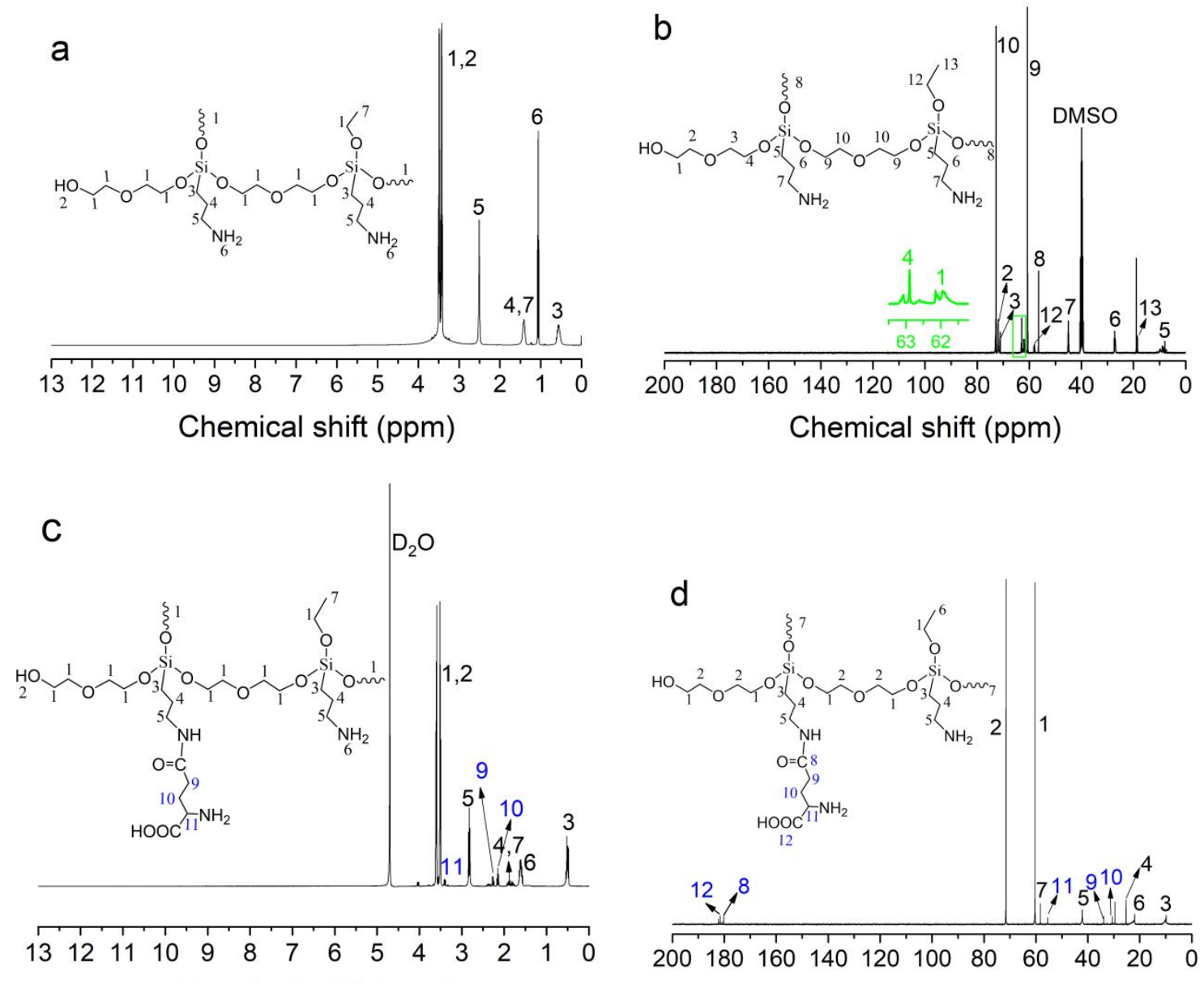

Chemical shift (ppm)

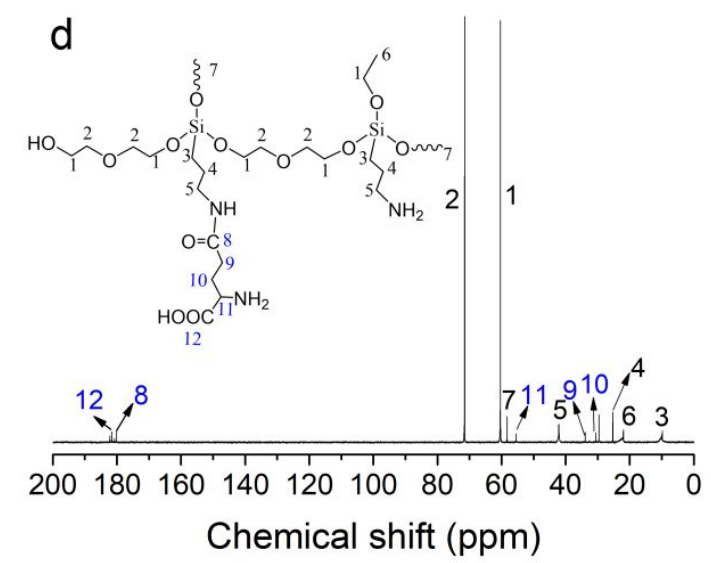

Figure S4. ${ }^{1} \mathrm{H}$ NMR spectra of HBPSi (a) and HBPSi-GA3 (c); ${ }^{13} \mathrm{C}$ NMR spectra of HBPSi (b) and HBPSi-GA3 (d). 

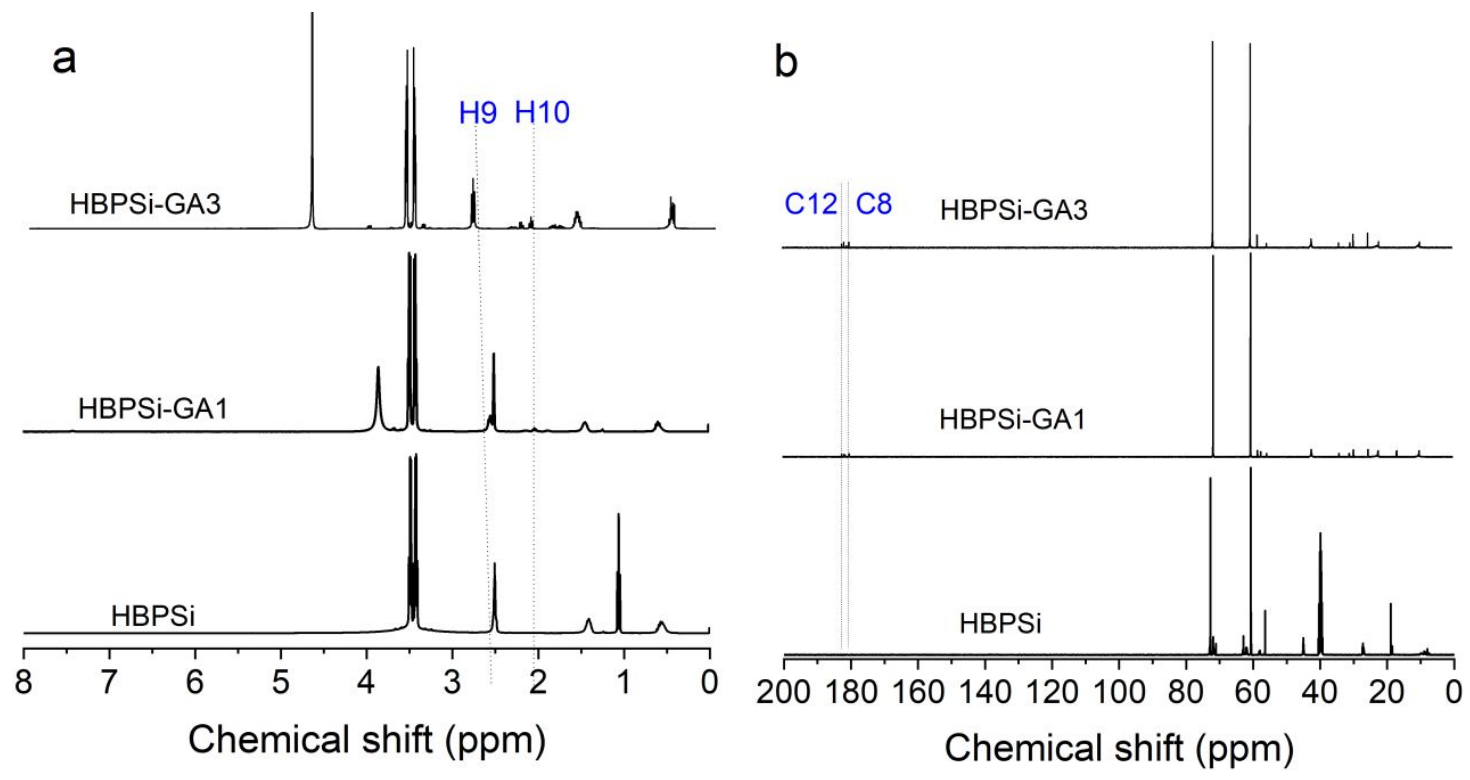

Figure S5. Comparison of the ${ }^{1} \mathrm{H}$ NMR spectra of HBPSi, HBPSi-GA1 and HBPSi-GA3 (a); ${ }^{13} \mathrm{C}$ NMR spectra of HBPSi, HBPSi-GA1 and HBPSi-GA3 (b).

Day light

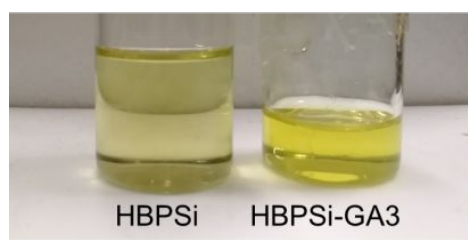

365 nm UV light

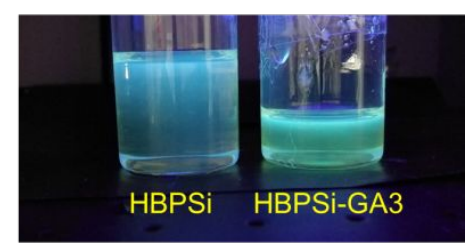

Figure S6. Digital pictures of pure HBPSi and pure HBPSi-GA3 under day light and $365 \mathrm{~nm}$ UV light.

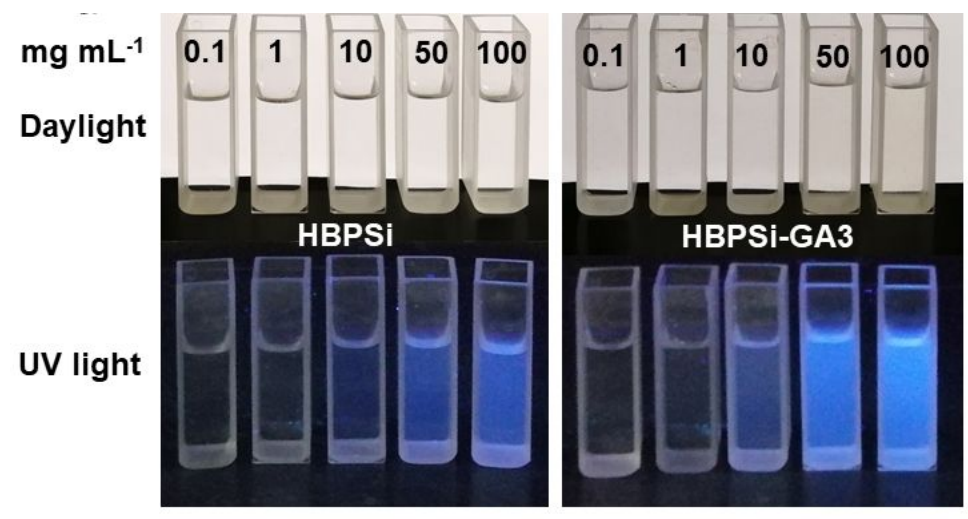

Figure S7. Digital pictures of different concentration of HBPSi and HBPSi-GA3 aqueous solutions under daylight and UV light. 


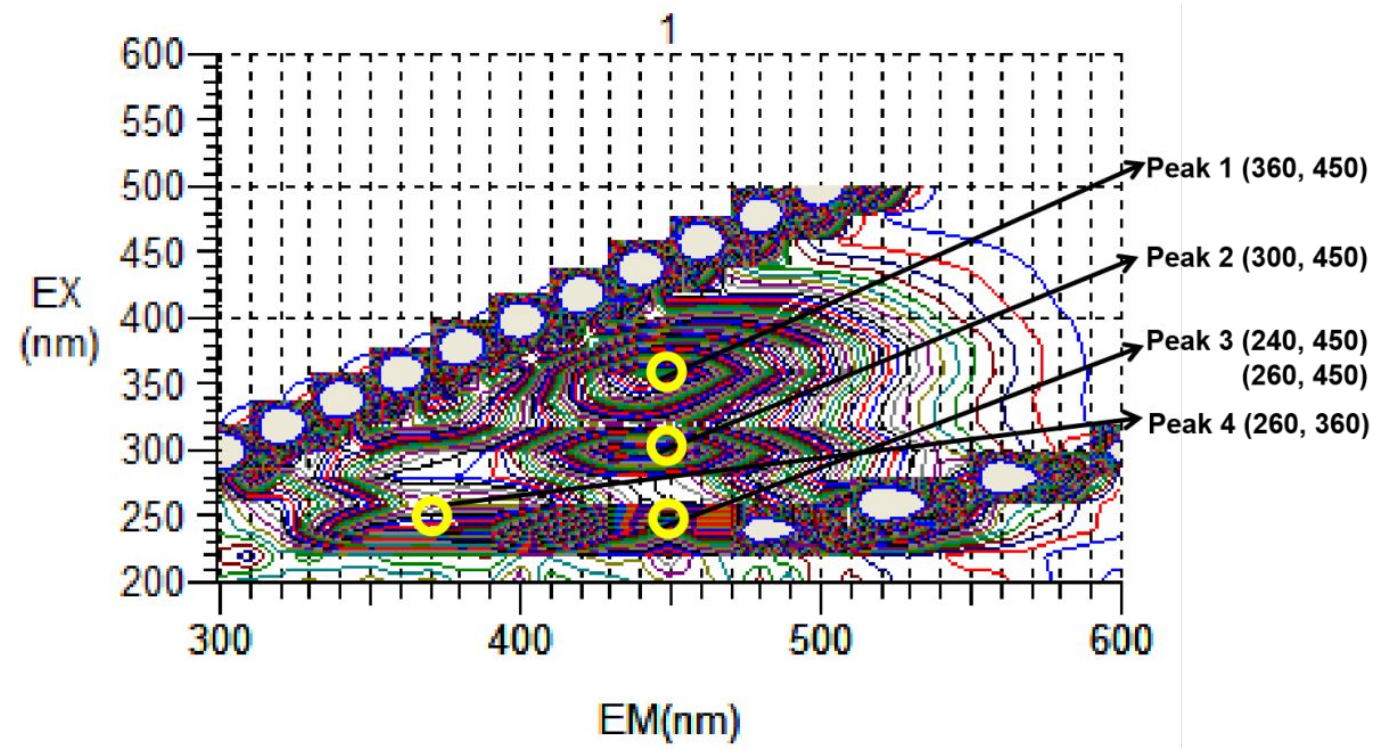

Figure S8. 3D scan spectrum of HBPSi-GA3 aqueous solution $\left(10 \mathrm{mg} \mathrm{mL}^{-1}\right.$; Excitation from 200 to $600 \mathrm{~nm}$, emission from 300 to $600 \mathrm{~nm}$ ).

To further check the multi-excitation and dual-emission property, 3D scan spectrum of HBPSi-GA3 is recorded. As shown in Figure S8, there are mainly five emission peaks at $(E x=260 \mathrm{~nm}, E m=380 \mathrm{~nm}),(E x=300 \mathrm{~nm}, E m=380 \mathrm{~nm}),(E x=240 \mathrm{~nm}, \mathrm{Em}=450 \mathrm{~nm}),(\mathrm{Ex}=300$ $\mathrm{nm}, \mathrm{Em}=450 \mathrm{~nm})$ and $(\mathrm{Ex}=360 \mathrm{~nm}, \mathrm{Em}=450 \mathrm{~nm})$. Thus, the $3 \mathrm{D}$ scan spectrum further confirm the multi-excitation and dual-emission property of HBPSi-GA3.

Table S2. The peak intensity of the four peaks in 3D scan spectrum of HBPSi-GA3 .

\begin{tabular}{cccc}
\hline Peak number & Ex peak $(\mathrm{nm})$ & Em peak $(\mathrm{nm})$ & Intensity \\
\hline 1 & $240(260)$ & 450 & 877.3 \\
2 & 280 & 380 & 312.6 \\
3 & 300 & 450 & 571.3 \\
4 & 360 & 450 & 568.5 \\
\hline
\end{tabular}




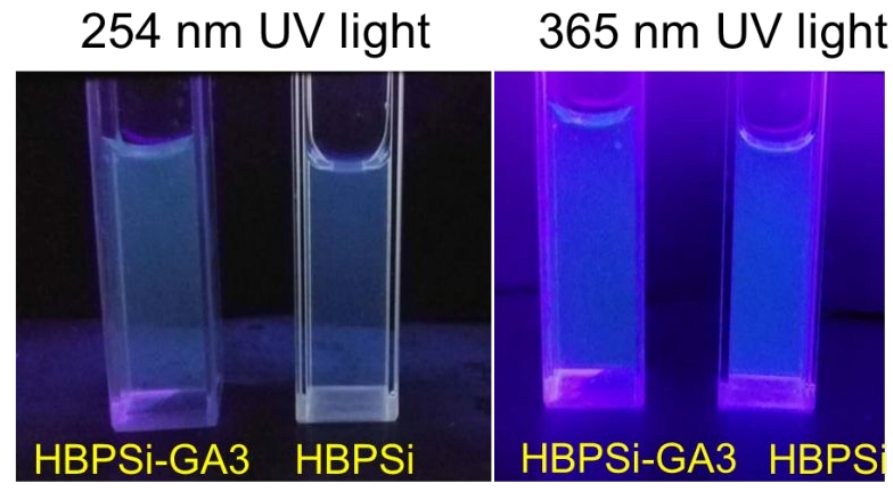

Figure S9. Digital pictures of HBPSi and HBPSi-GA3 under 254 and $365 \mathrm{~nm}$ UV light (10 mg $\left.\mathrm{mL}^{-1}\right)$.
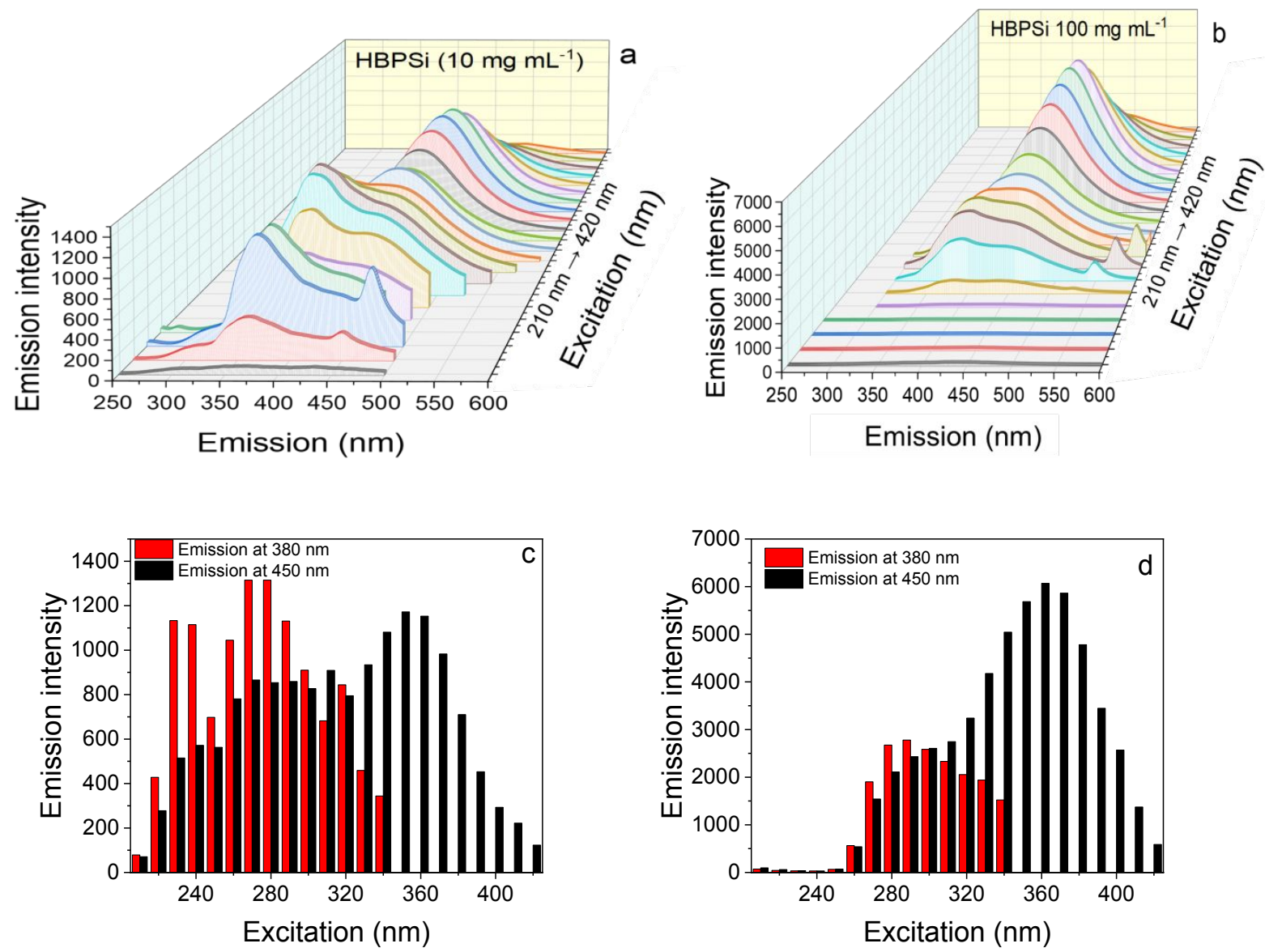

Figure S10. Emission spectra of HBPSi under excitation from 210 to $420 \mathrm{~nm}$ in $10 \mathrm{mg} \mathrm{mL}^{-1}$ (a) and $100 \mathrm{mg} \mathrm{mL}^{-1}$ (b) water solution, respectively. Emission intensity of HBPSi under different excitations: 10 (c) and 100 (d) $\mathrm{mg} \mathrm{mL}^{-1}$ water solution.

In addition, the Commission Internationale de L'Eclairage (CIE) chromaticity coordinates of HBPSi-GA3 in 10 and $100 \mathrm{mg} \mathrm{mL}^{-1}$ water solution are obtained, they are calculated from the 
corresponding emission spectra in Figure $4 \mathbf{a}$ and $\mathbf{4 b}$. In Figure S11a and S11b, the CIE chromaticity coordinates of HBPSi-GA3 mainly locates at blue region when the under excitation of 240-370 nm, while changes from blue to cyan color with increasing the excitation wavelength from 370 to $420 \mathrm{~nm}$. Furthermore, the emission color obtained under excitation of 240 and $260 \mathrm{~nm}$ is red-shifted as the concentration increases from 10 to $100 \mathrm{mg} \mathrm{mL}^{-1}$. Most recent studies found that the excitation-independent emission of unconventional polymer is closely related to the formed heterogeneous electron delocalization. ${ }^{1-4}$ Therefore, heterogenous electron delocalizations exist in the aggregates of HBPSi-GA3. To check the blue emission in wide excitation range, digital pictures of HBPSi-GA3 excited by 254 and $365 \mathrm{~nm}$ UV light are obtained. As shown in Figure S9, the $10 \mathrm{mg} \mathrm{mL}^{-1}$ HBPSi-GA3 and HBPSi water solution can emit blue light under 254 and $365 \mathrm{~nm}$ UV light. Thus, compared with other unconventional fluorescent polymers ${ }^{2}$ 5-10, the as-prepared HBPSi-GA3 can emit blue color in a much wider range of excitation, which endows HBPSi-GA3 with ability to resist the interference of background light. As Figure S10, S11c and S11d show, HBPSi shows similar fluorescence property with HBPSi-GA3.

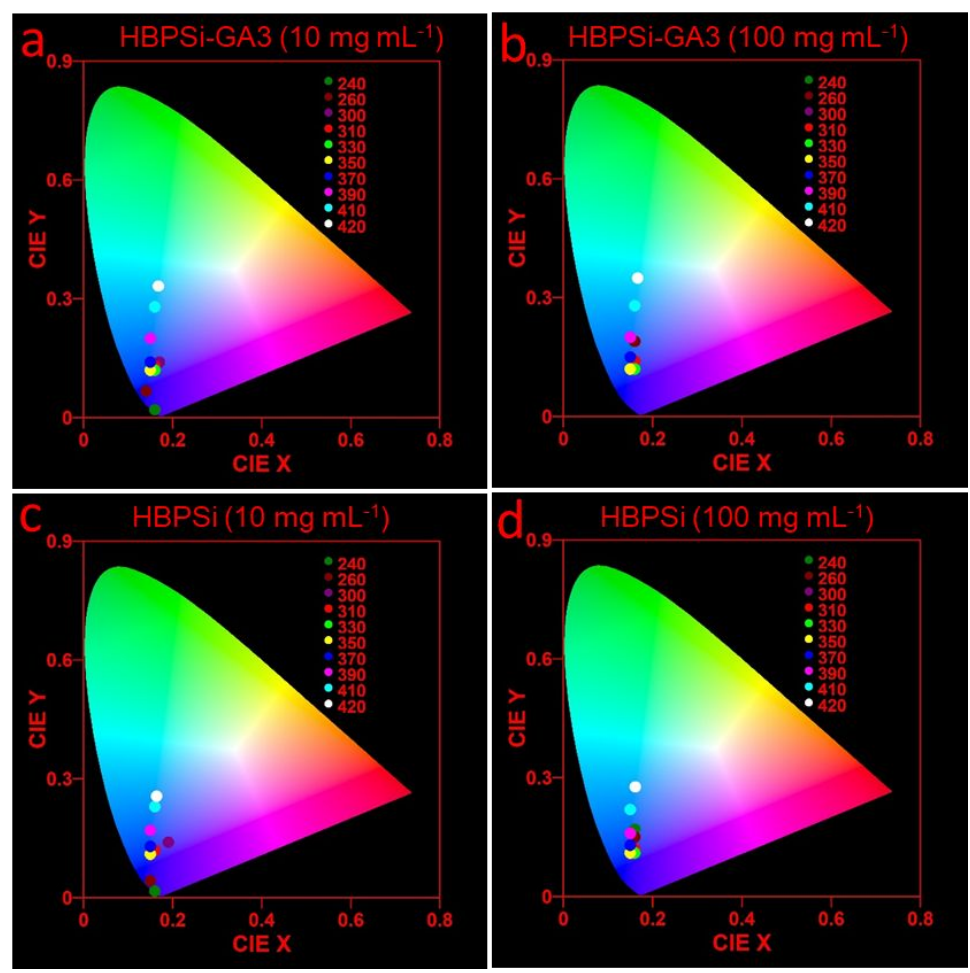

Figure S11. CIE color coordinates of HBPSi-GA3: $10 \mathrm{mg} \mathrm{mL}^{-1}$ (a) and $100 \mathrm{mg} \mathrm{mL}^{-1}$ (b) water solution. CIE color coordinates of HBPSi: $10 \mathrm{mg} \mathrm{mL}^{-1}$ (c) and $100 \mathrm{mg} \mathrm{mL}^{-1}$ (d) water solution. 

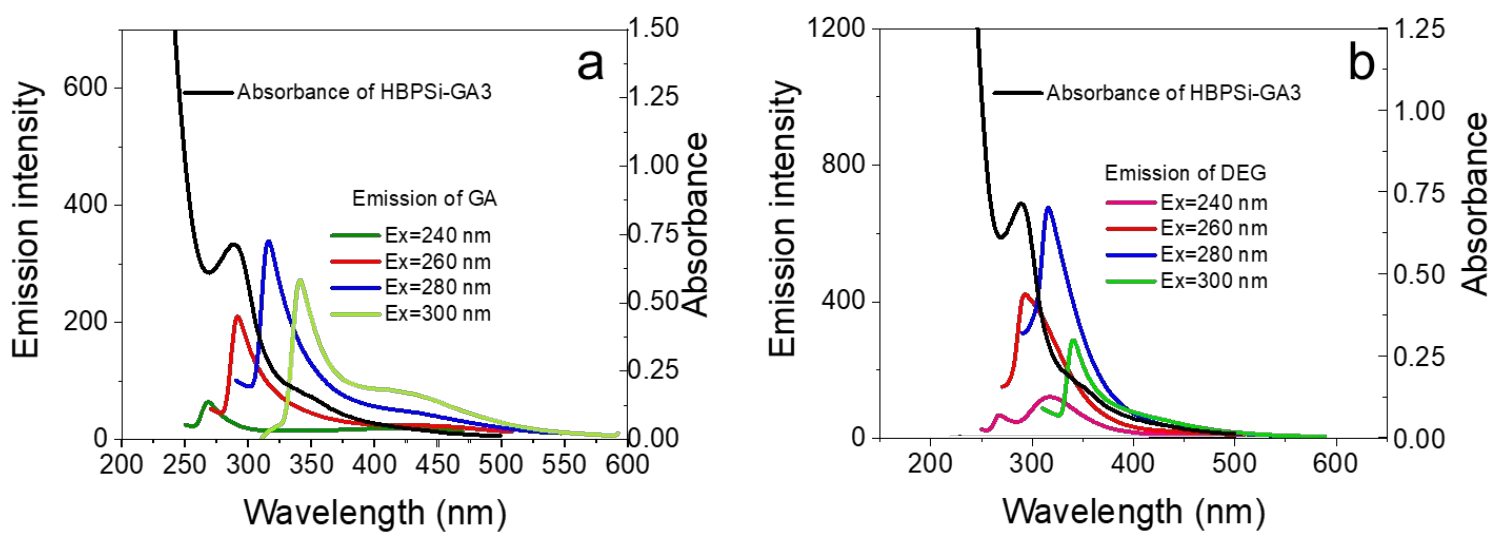

Figure S12. The spectral overlap between the emission of L-glutamic acid and the absorption of HBPSi-GA3 (a). The spectral overlap between the emission of diethylene glycol and the absorption of HBPSi-GA3 (b). Emission spectra of L-glutamic acid and diethylene glycol are obtained under excited by 240, 260, 280 and $300 \mathrm{~nm}$, respectively. Concentration of HBPSi water solution: $10 \mathrm{mg} \mathrm{mL}^{-1}$.
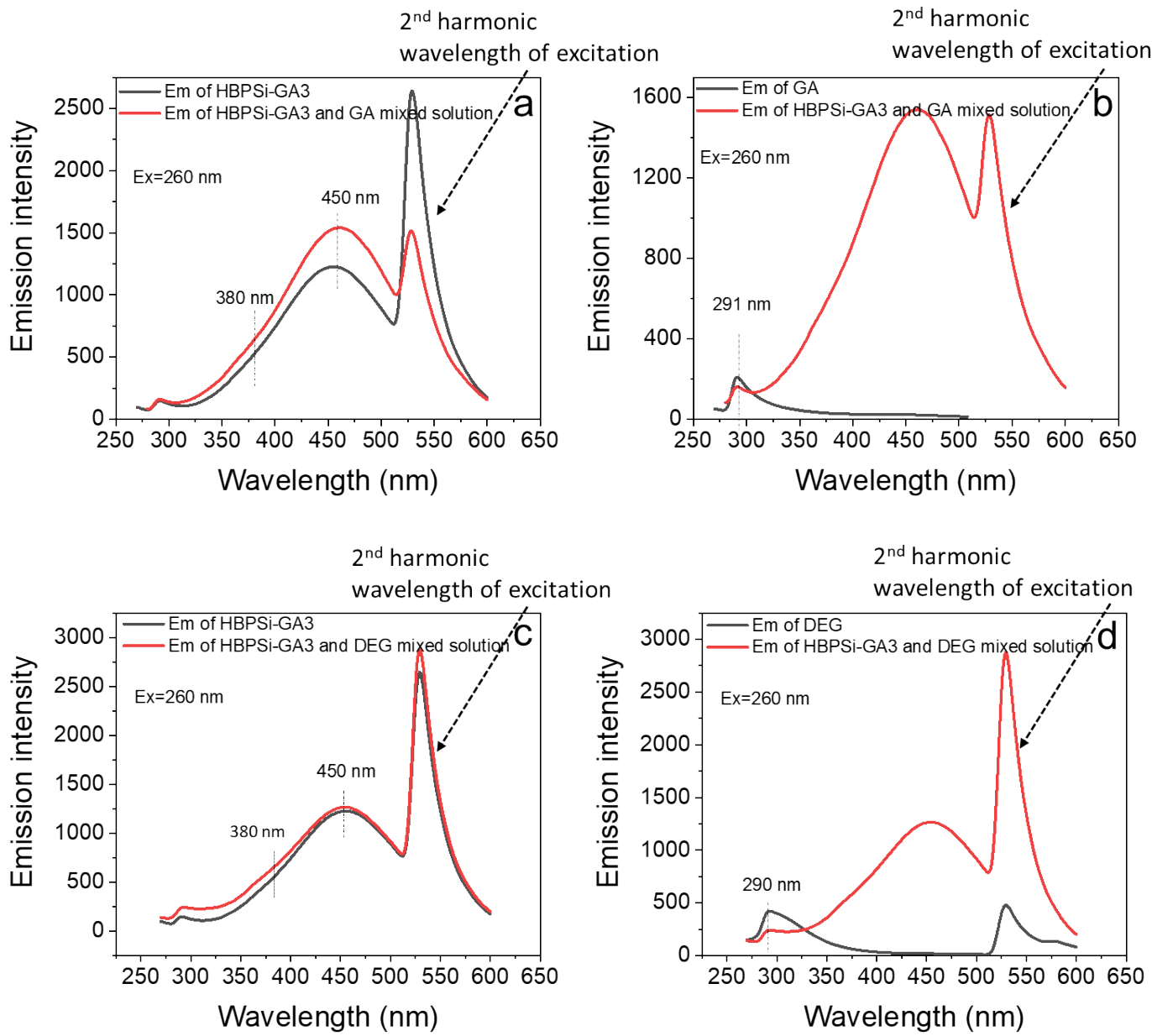

Figure S13. The emission spectra of HBPSi-GA3 under excitation of $260 \mathrm{~nm}$ UV light: before and after adding GA (a) and DEG (c). The Emission spectra of GA (b) and DEG (d) before and after mixing with HBPSi-GA3. Concentration of HBPSi water solution: $10 \mathrm{mg} \mathrm{mL}^{-1}$. 


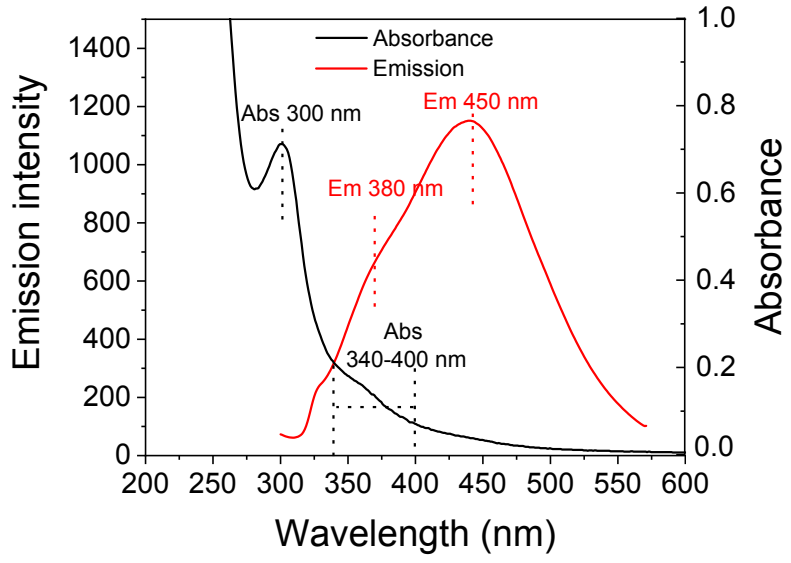

Figure S14. Spectral overlap between the absorbance peak at 340-400 and emission peak at $380 \mathrm{~nm}$. Emission spectrum of HBPSi-GA3 is obtained under excitation of $300 \mathrm{~nm}$. Concentration of HBPSi-GA3 water solution: $10 \mathrm{mg} \mathrm{mL}^{-1}$.

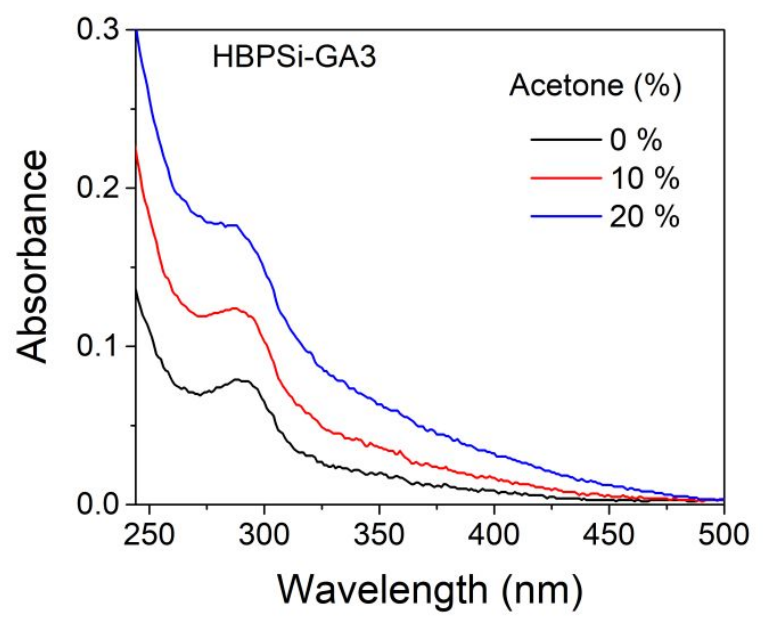

Figure S15. UV-vis absorbance spectra of HBPSi-GA3 in water-acetone mixture (concentration, $5 \mathrm{mg} \mathrm{mL}^{-1}$ ).

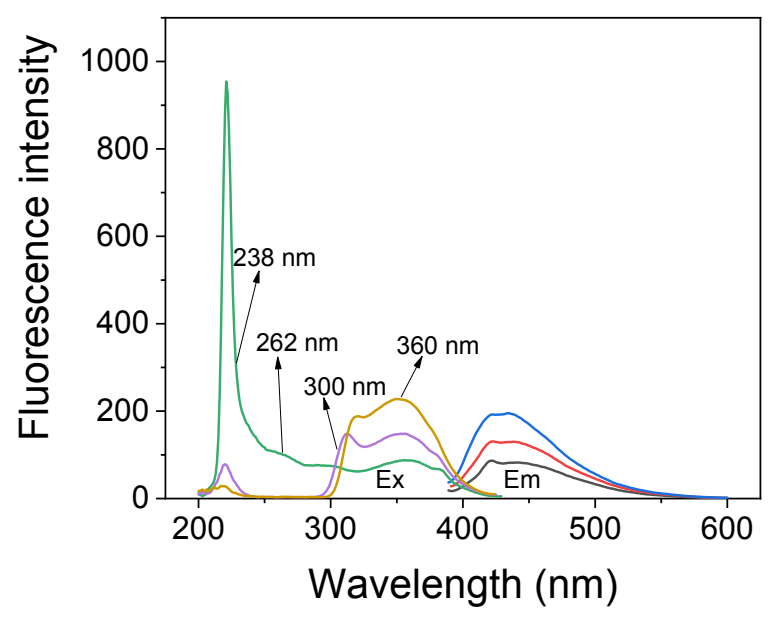

Figure S16. Fluorescence spectra of HBPSi in water-acetone mixture solution $\left(1 \mathrm{mg} \mathrm{mL}^{-1}\right)$. 

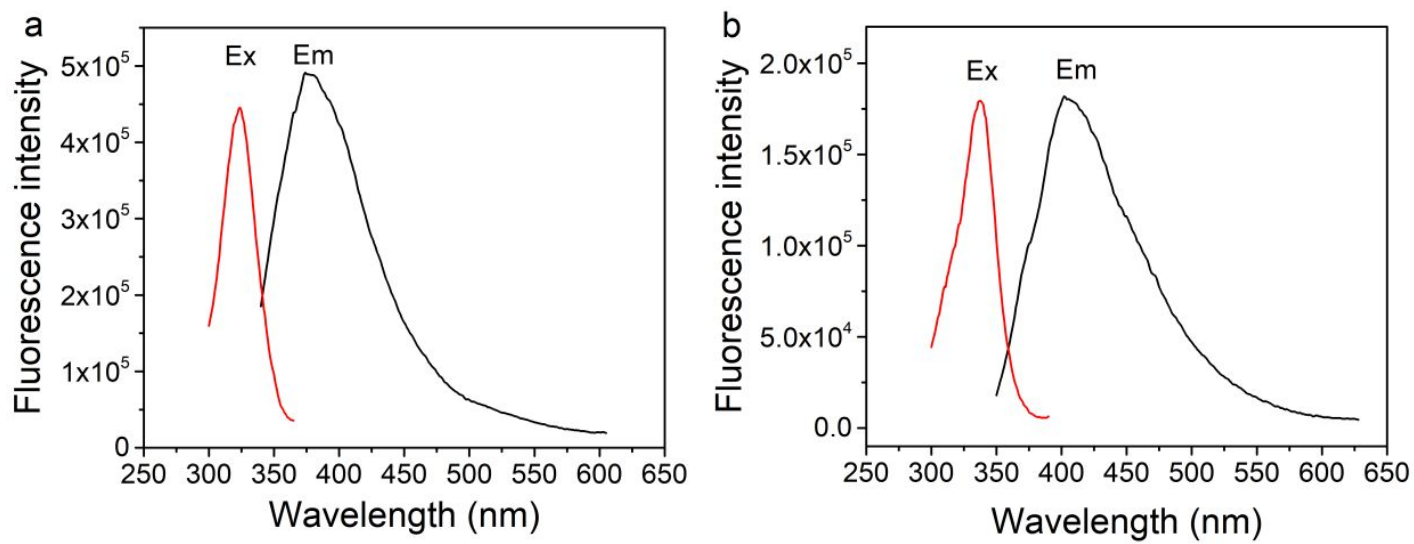

Figure S17. Fluorescence spectra of pure HBPSi (a) and HBPSi-GA3 (b).

Figure S17 is the fluorescence spectra of pure HBPSi (a) and HBPSi-GA3. The excitation and emission peaks of HBPSi center at about 324 and $382 \mathrm{~nm}$, respectively. However, after Lglutamic acid is introduced onto HBPSi, the excitation and emission peaks of HBPSi-GA3 locates at about 337 and $406 \mathrm{~nm}$. Thus, compared with HBPSi, HBPSi-GA3 has longer excitation and emission wavelength, which is caused by the enlargement of electron delocalization due to the introduced L-glutamic acid.

The absolute quantum yields (QY) and fluorescence lifetimes of pure HBPSi and HBPSiGA3 were measured. As shown in Figure S18, the transient photoluminescence decay curve of HBPSi is located at $374 \mathrm{~nm}$ under excitation at $324 \mathrm{~nm}$. The decay curve was then fitted on the nonlinear least-squares analysis via the following equation: $R(t)=B_{1} \exp \left(-t / \tau_{1}\right)+B_{2} \exp \left(-t / \tau_{2}\right)$ $+B_{3} \exp \left(-t / \tau_{3}\right)$, where $B_{1}, B_{2}$ and $B_{3}$ are the fractional contributions of the time-resolved decay lifetimes of $\tau_{1}, \tau_{2}$ and $\tau_{3}$, respectively. Then, the average fluorescence lifetimes $\left(\tau_{\text {avg }}\right)$ of the polymers were calculated by $\tau_{\text {avg }}=\left(B_{1} \tau_{1}^{2}+B_{2} \tau_{2}^{2}+B_{3} \tau_{3}^{2}\right) /\left(B_{1} \tau_{1}+B_{2} \tau_{2}+B_{3} \tau_{3}\right)$. The decay curves of HBPSi and HBPSi-GA3 fit the double exponential function, and the $\tau_{\text {avg }} \mathrm{s}$ of HBPSi and HBPSi-GA3 are 27.0 and $28.8 \mathrm{~ns}$, respectively. The absolute quantum yields of HBPSi and HBPSi-GA3 are 8.8 and $11.8 \%$, respectively. The increase of quantum yield could be caused by the introduction of amide groups, which leads to the enhancement of the hydrogen bonds, and finally increases the aggregation degree of the polymers. 

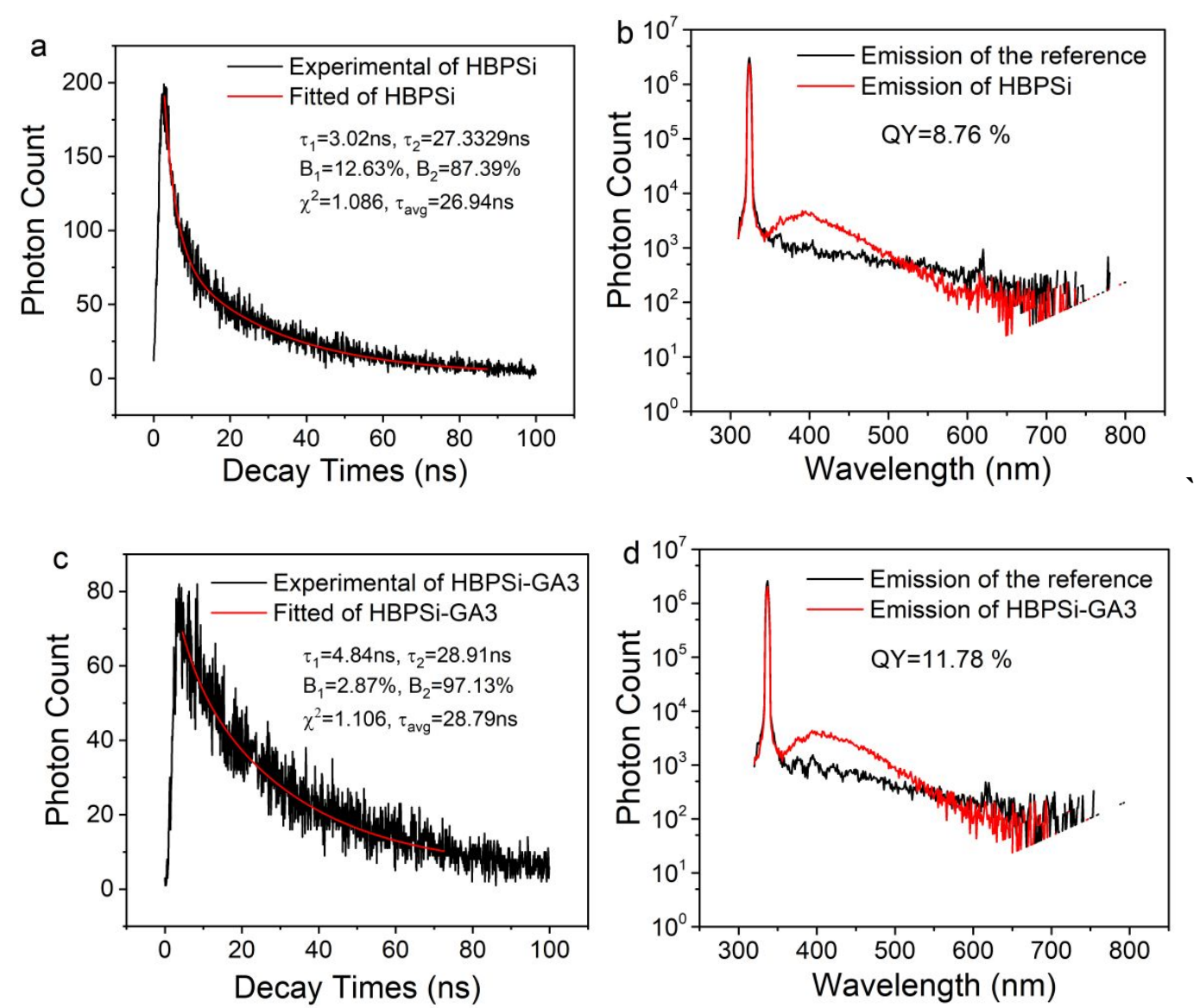

Figure S18. The transient photoluminescence decay curves of HBPSi at $374 \mathrm{~nm}$ after excitation at $324 \mathrm{~nm}$ (a) and HBPSi-GA3 at $402 \mathrm{~nm}$ after excited by $337 \mathrm{~nm}$ excitation (c); the absolute fluorescence quantum yield (QY) of HBPSi excited at $324 \mathrm{~nm}(\mathrm{~b})$ and HBPSi-GA3 excited at $337 \mathrm{~nm}(\mathrm{~d})$.

Table S3. Fluorescence lifetime $(\tau)$ and quantum yields $(\Phi)$ of HBPSi and HBPSi-GA3

\begin{tabular}{ccccc}
\hline sample & $\lambda_{\text {ex }}(\mathrm{nm})$ & $\lambda_{\text {em }}(\mathrm{nm})$ & $\tau(\mathrm{ns})$ & $\Phi(\%)$ \\
\hline HBPSi & 324 & 374 & 27.0 & 8.8 \\
HBPSi-GA3 & 337 & 402 & 28.8 & 11.8 \\
\hline
\end{tabular}




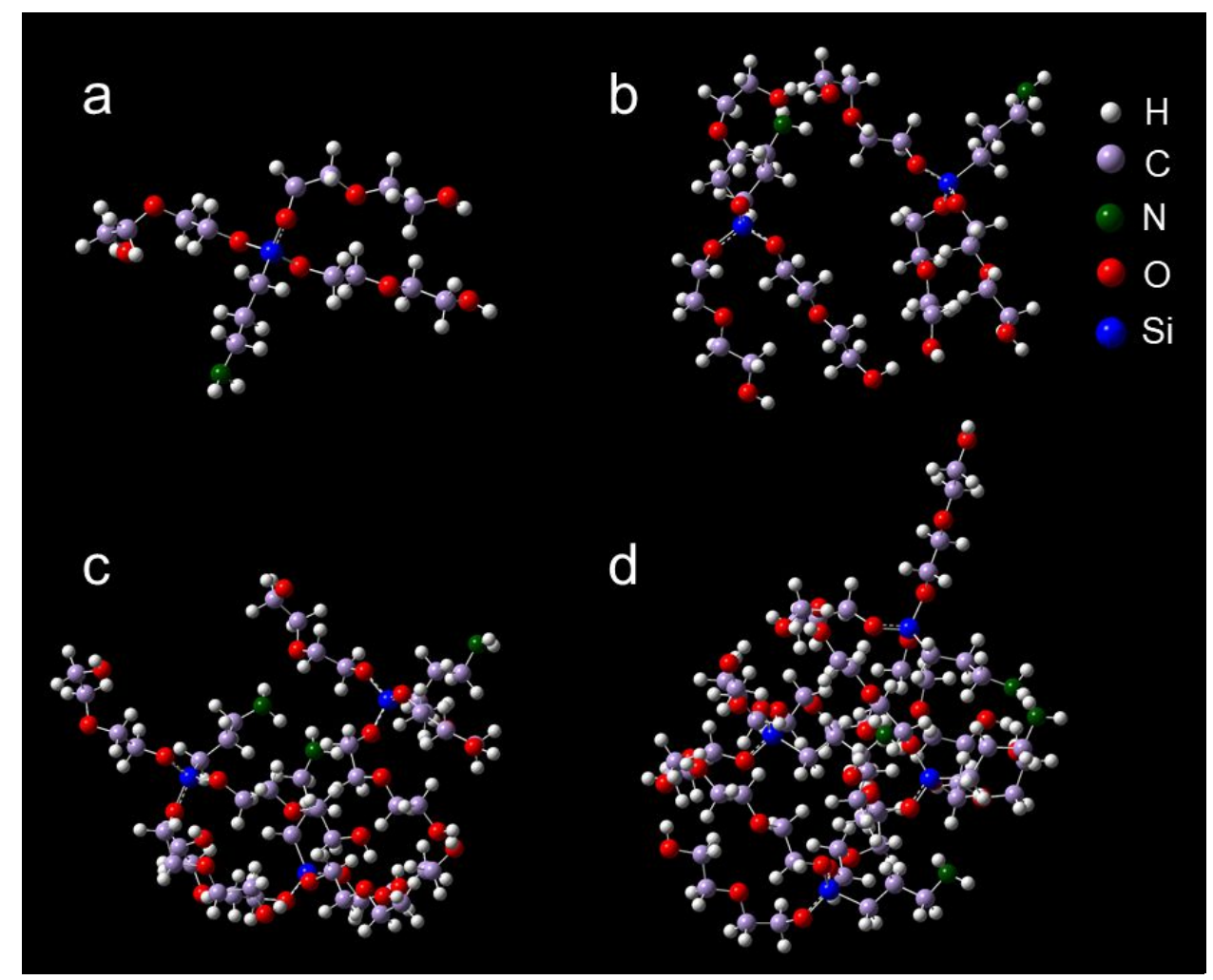

Figure S19. Optimized conformations of various HBPSi molecules: one molecule (a), two molecules (b), three molecules (c) and four molecules (d) (DFT method at B3LYP/6-31G(d,g) level).

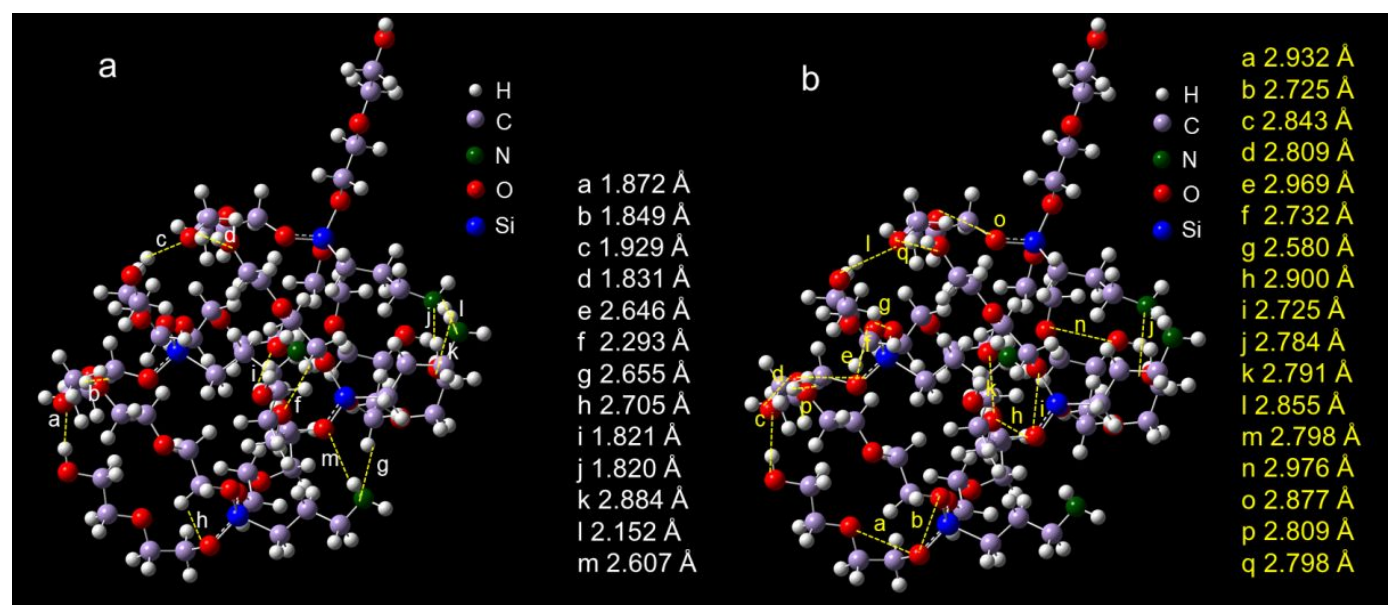

Figure S20. Hydrogen bonds between four HBPSi molecules (a). Intramolecular and intermolecular $\mathrm{O} \cdots \mathrm{O}$ and $\mathrm{O} \cdots \mathrm{N}$ interactions in four HBPSi molecules (b). 


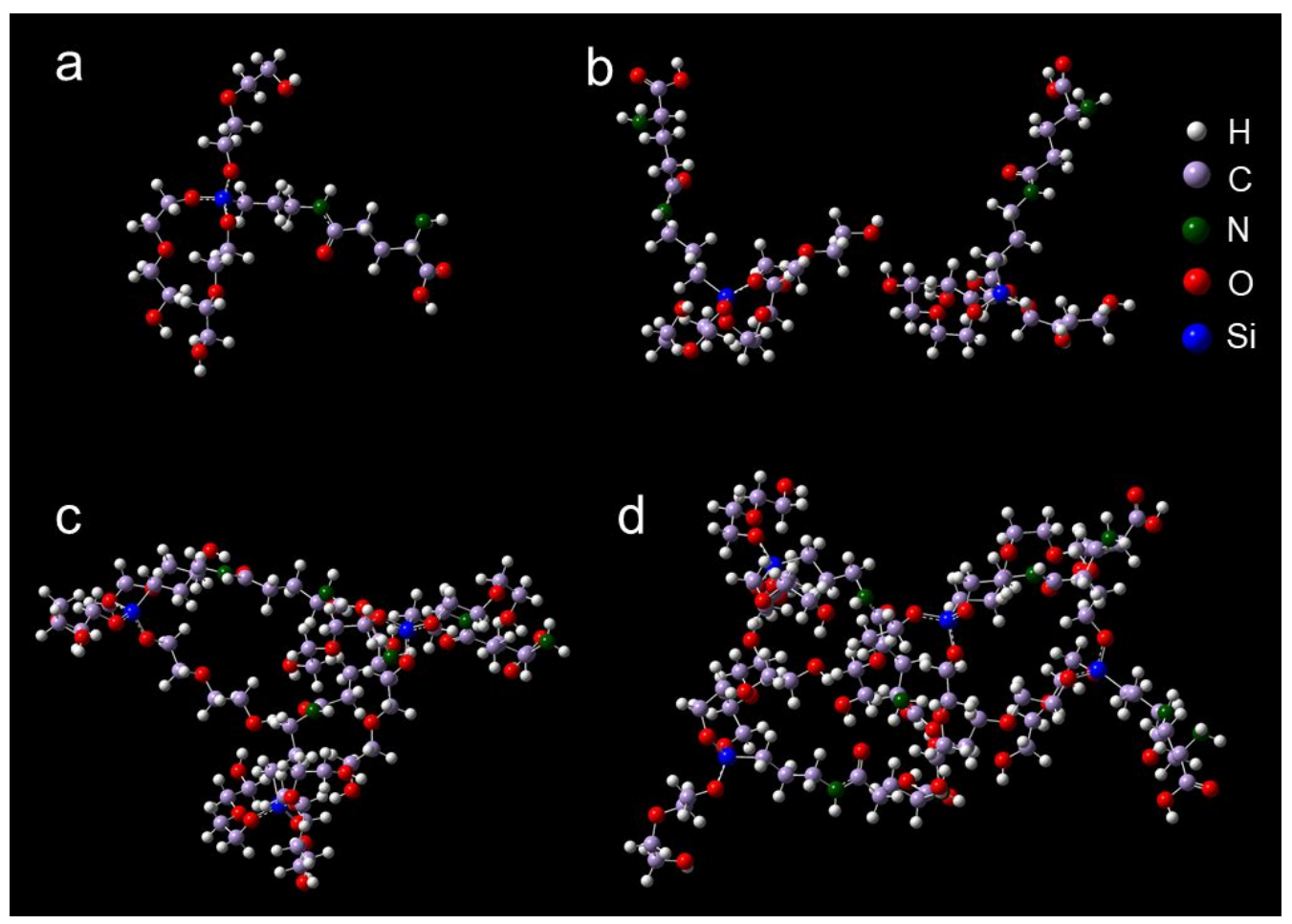

Figure S21. Optimized conformations of various HBPSi-GA molecules: one molecule (a), two molecules (b), three molecules (c) and four molecules (d) (DFT method at B3LYP/6-31G(d,g) level).

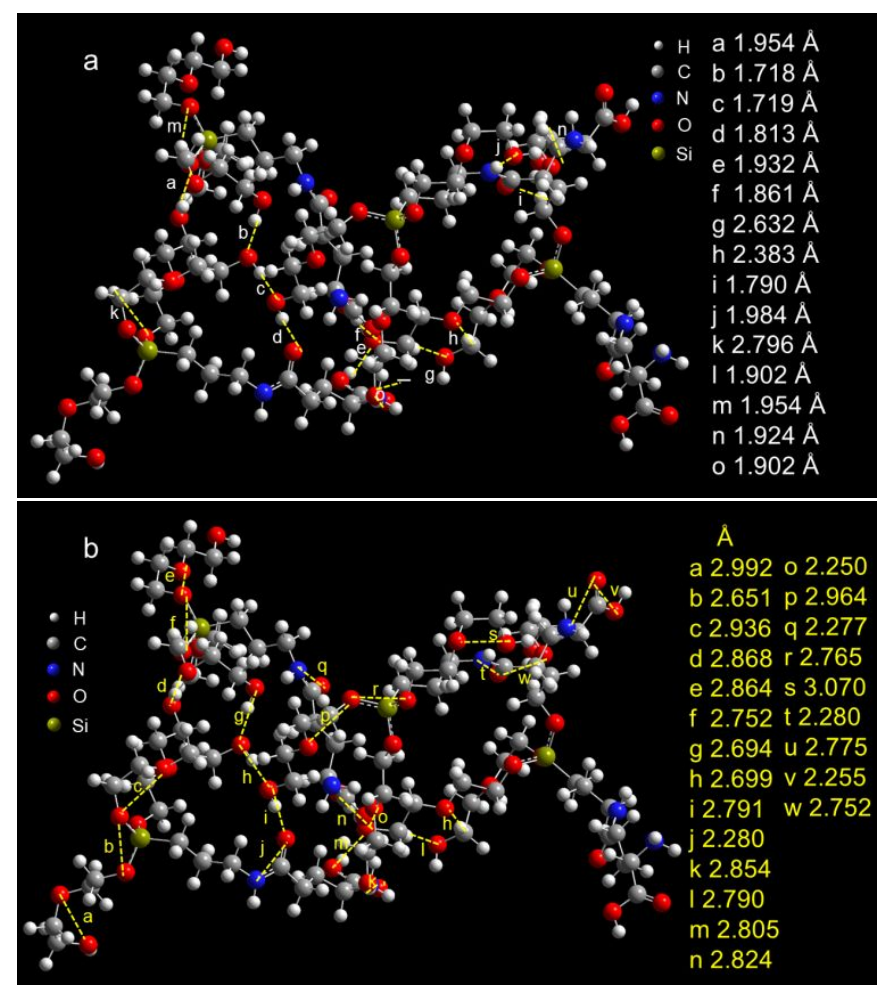

Figure S22. Hydrogen bonds between four HBPSi-GA molecules (a). Intramolecular and intermolecular $\mathrm{O} \cdots \mathrm{O}$ and $\mathrm{O} \cdots \mathrm{N}$ interactions in four HBPSi-GA molecules (b). 
Table S4. DFT calculation results of HOMO-LUMO energy levels of the conformations with various molecules (DFT method at B3LYP/6-31G(d,g) level).

\begin{tabular}{ccccccc}
\hline \multirow{2}{*}{ sample } & Molecule number & $\mathrm{HOMO} / \mathrm{eV}$ & $\mathrm{H}-1 / \mathrm{eV}$ & $\mathrm{LUMO} / \mathrm{eV}$ & $\mathrm{L}+1 / \mathrm{eV}$ & $\mathrm{HOMO}-\mathrm{LUMO} / \mathrm{eV}$ \\
\cline { 2 - 7 } & 1 & -6.205 & -6.594 & 1.446 & 1.602 & 7.374 \\
HBPSi & 2 & -6.027 & -6.232 & 0.971 & 1.409 & 7.020 \\
& 3 & -5.596 & -6.182 & 0.982 & 1.270 & 6.585 \\
& 4 & -5.968 & -6.140 & 0.946 & 1.065 & 6.884 \\
\multirow{3}{*}{ HBPSi-GA } & 1 & -6.495 & -6.616 & 0.136 & 1.026 & 6.612 \\
& 2 & -6.450 & -6.520 & 0.123 & 0.163 & 6.558 \\
& 3 & -6.348 & -6.456 & -0.299 & -0.080 & 6.041 \\
\hline
\end{tabular}

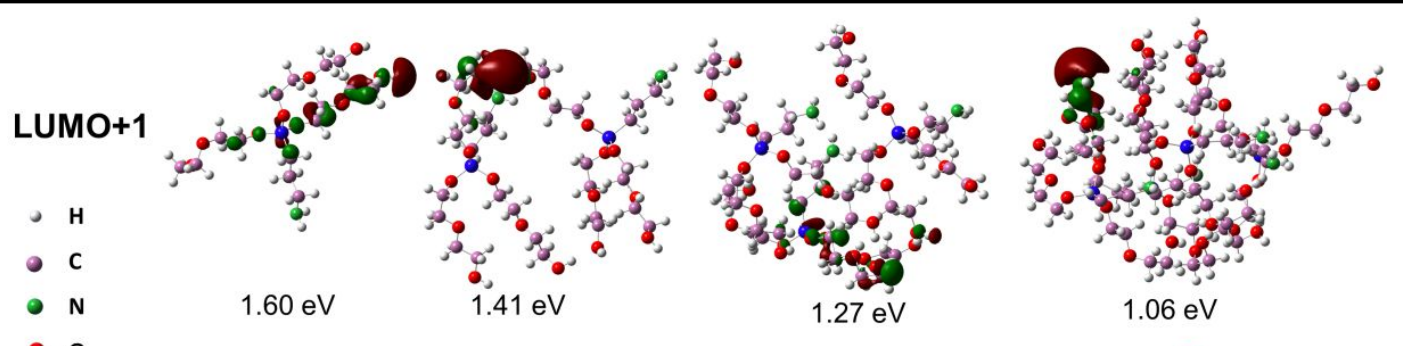

- 0

- $\mathrm{Si}$

LUMO

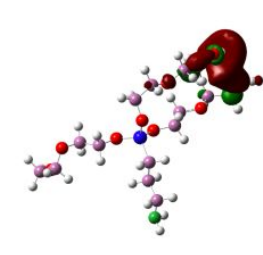

$1.45 \mathrm{eV}$

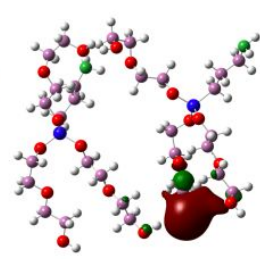

$0.97 \mathrm{eV}$
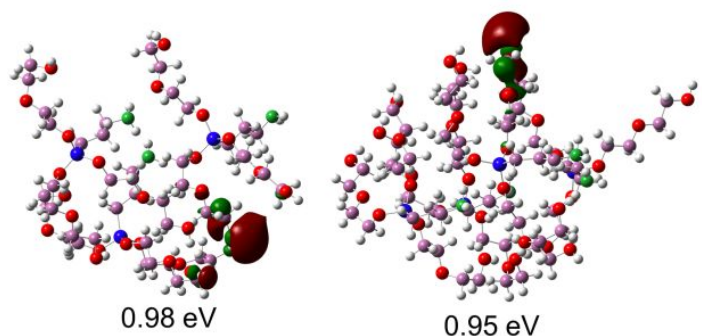

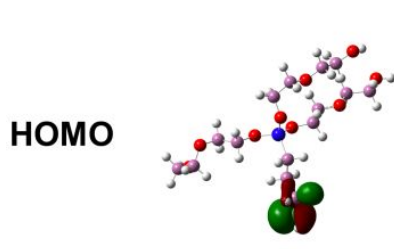

$-6.20 \mathrm{eV}$

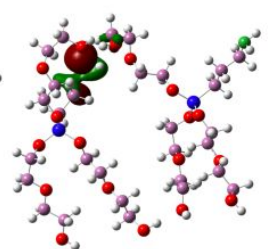

$-6.03 \mathrm{eV}$
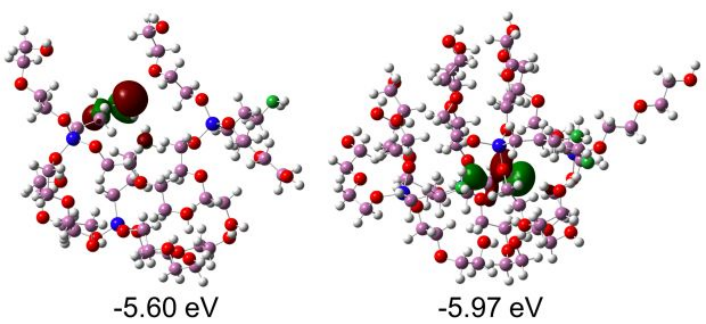

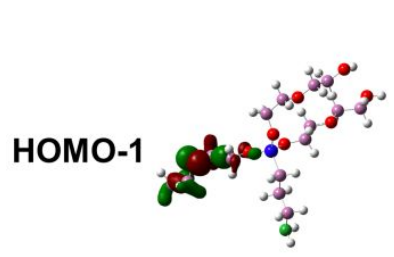

$-6.59 \mathrm{eV}$

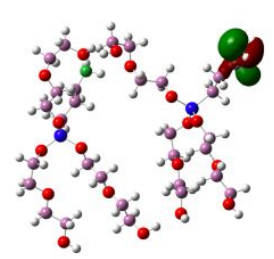

$-6.23 \mathrm{eV}$

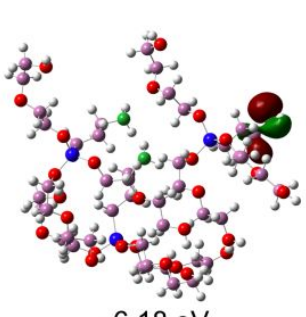

$-6.18 \mathrm{eV}$

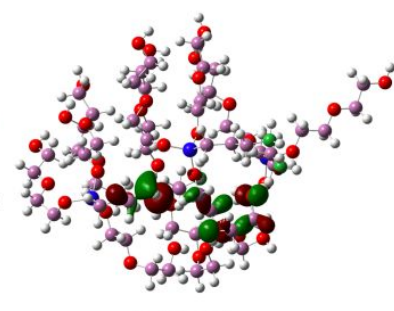

$-6.14 \mathrm{eV}$

One molecule Two molecules Three molecules Four molecules

Figure S23. Frontier orbitals of HBPSi with one, two, three and four molecules at the S0 geometries using the DFT method at B3LYP/6-31G(d,g) level. 


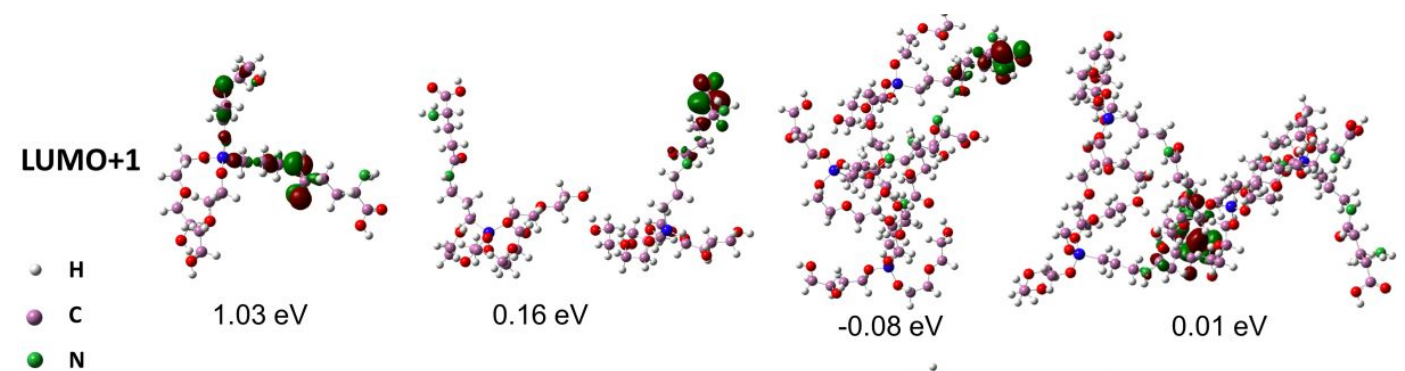

- $N$

- 0

- Si

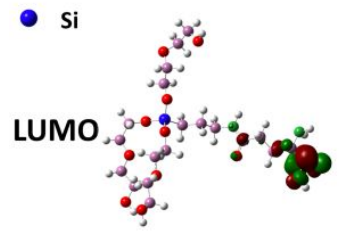

$0.14 \mathrm{eV}$

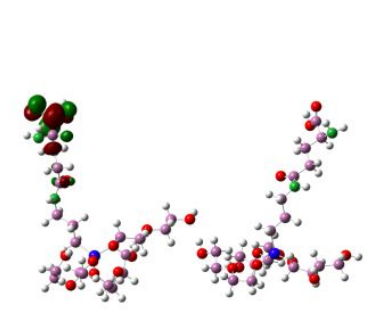

$0.12 \mathrm{eV}$

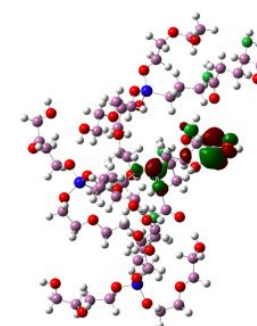

$-0.30 \mathrm{eV}$

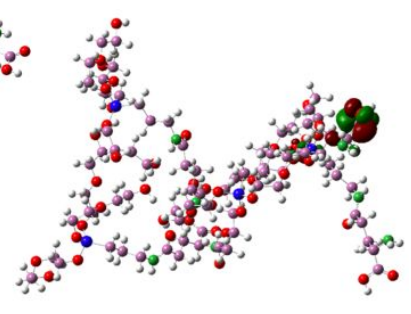

$-0.42 \mathrm{eV}$

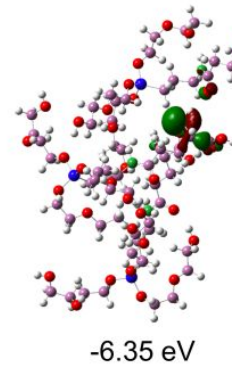

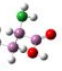
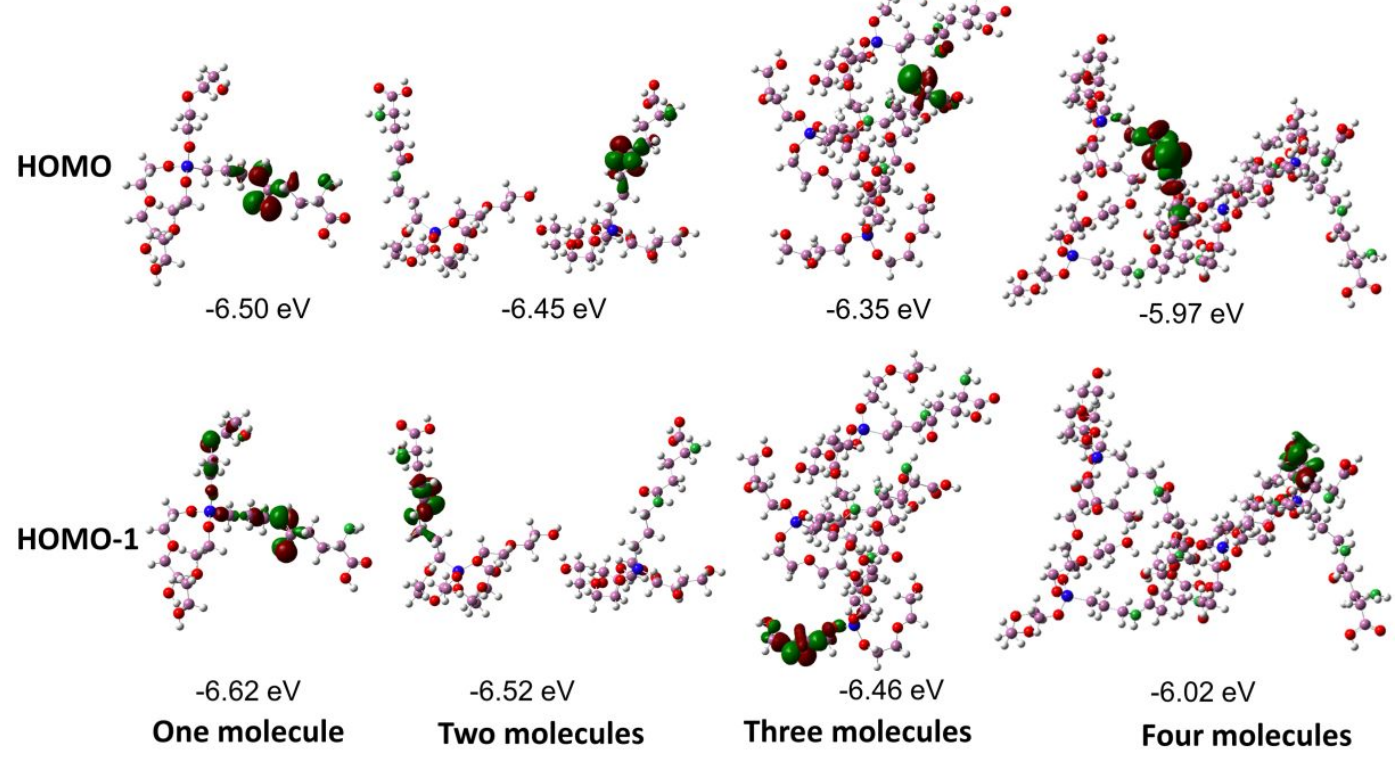

Figure S24. Frontier orbitals of HBPSi-GA with one, two, three and four molecules at the S0 geometries using the DFT method at B3LYP/6-31G(d,g) level. 


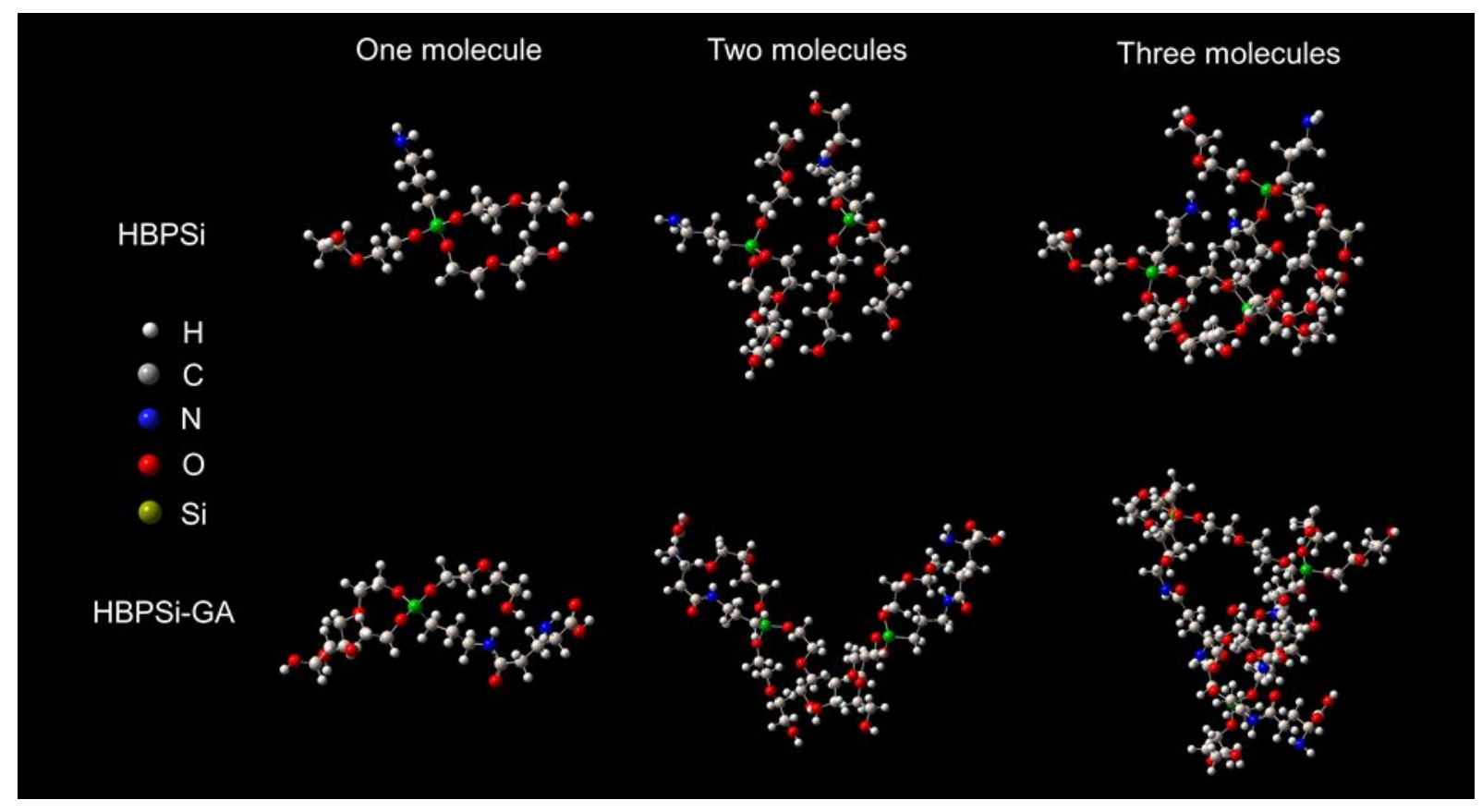

Figure S25. Optimized conformations of HBPSi and HBPSi-GA molecules: one molecule, two molecules and three molecules (DFT method at M062X/6-31G(d,g) level).

Table S5. DFT calculation results of HOMO-LUMO energy levels of the conformations with various molecules (DFT method at M062X/6-31G(d,g) level).

\begin{tabular}{ccccccc}
\hline sample & Molecule number & $\mathrm{HOMO} / \mathrm{eV}$ & $\mathrm{H}-1 / \mathrm{eV}$ & $\mathrm{LUMO} / \mathrm{eV}$ & $\mathrm{L}+1 / \mathrm{eV}$ & $\mathrm{HOMO}-\mathrm{LUMO} / \mathrm{eV}$ \\
\hline \multirow{3}{*}{ HBPSi } & 1 & -8.01 & -8.41 & 2.58 & 2.76 & 10.59 \\
& 2 & -7.79 & -7.97 & 2.46 & 2.50 & 10.25 \\
& 3 & -7.21 & -7.97 & 2.08 & 2.23 & 9.29 \\
\hline \multirow{3}{*}{ HBPSi-GA } & 1 & -7.90 & -8.26 & 0.88 & 2.38 & 8.78 \\
& 2 & -7.82 & -7.94 & 0.86 & 0.92 & 8.68 \\
& 3 & -8.26 & -8.42 & 1.11 & 1.26 & 9.37 \\
\hline
\end{tabular}




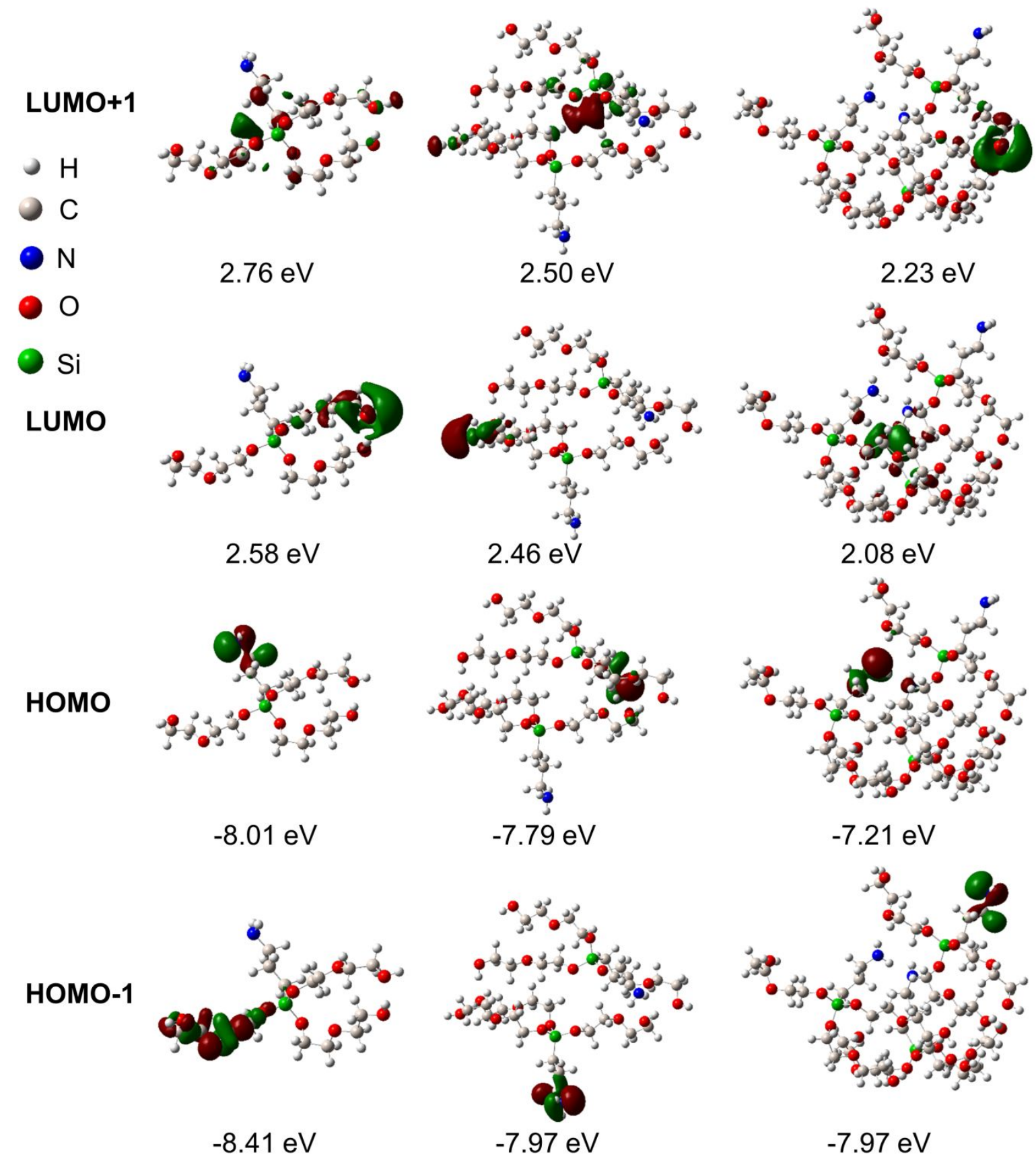

One molecule

Two molecules

Three molecules

Figure S26. Frontier orbitals of HBPSi with one, two and three at the S0 geometries using the DFT method at M062X/6-31G(d,g) level. 

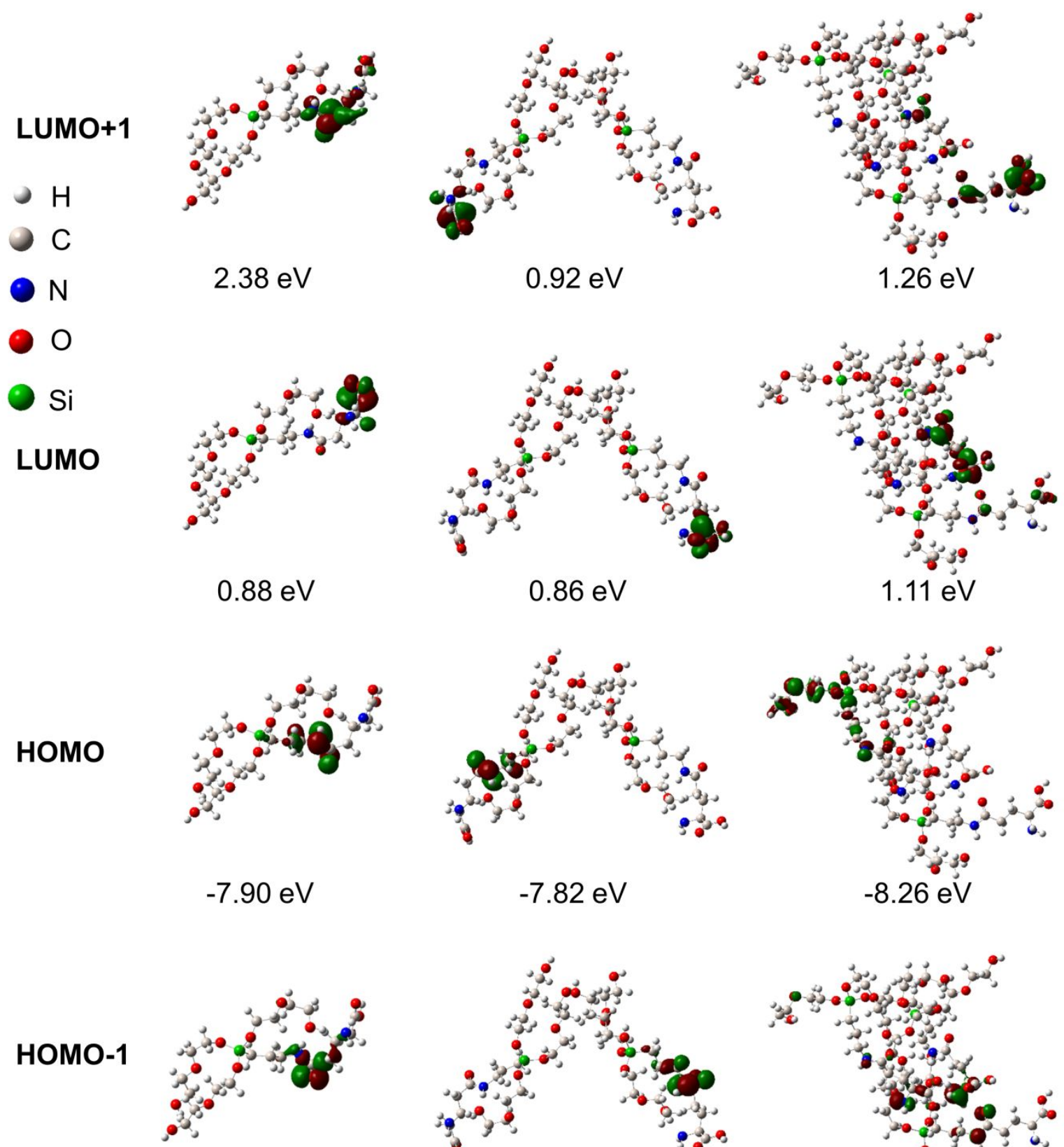

$$
-8.26 \mathrm{eV}
$$

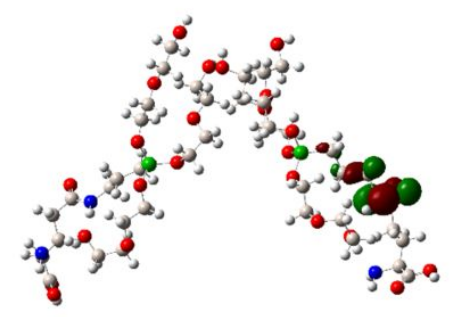

$-7.94 \mathrm{eV}$

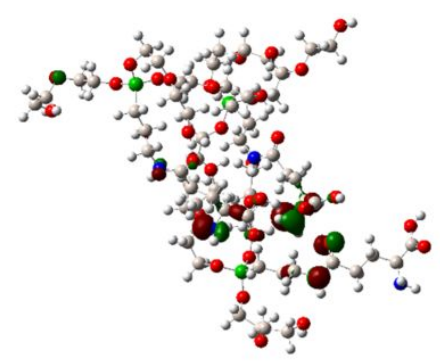

$-8.42 \mathrm{eV}$

\section{One molecule}

Two molecules

Three molecules

Figure S27. Frontier orbitals of HBPSi-GA3 with one, two and three at the S0 geometries using the DFT method at M062X/6-31G(d,g) level. 


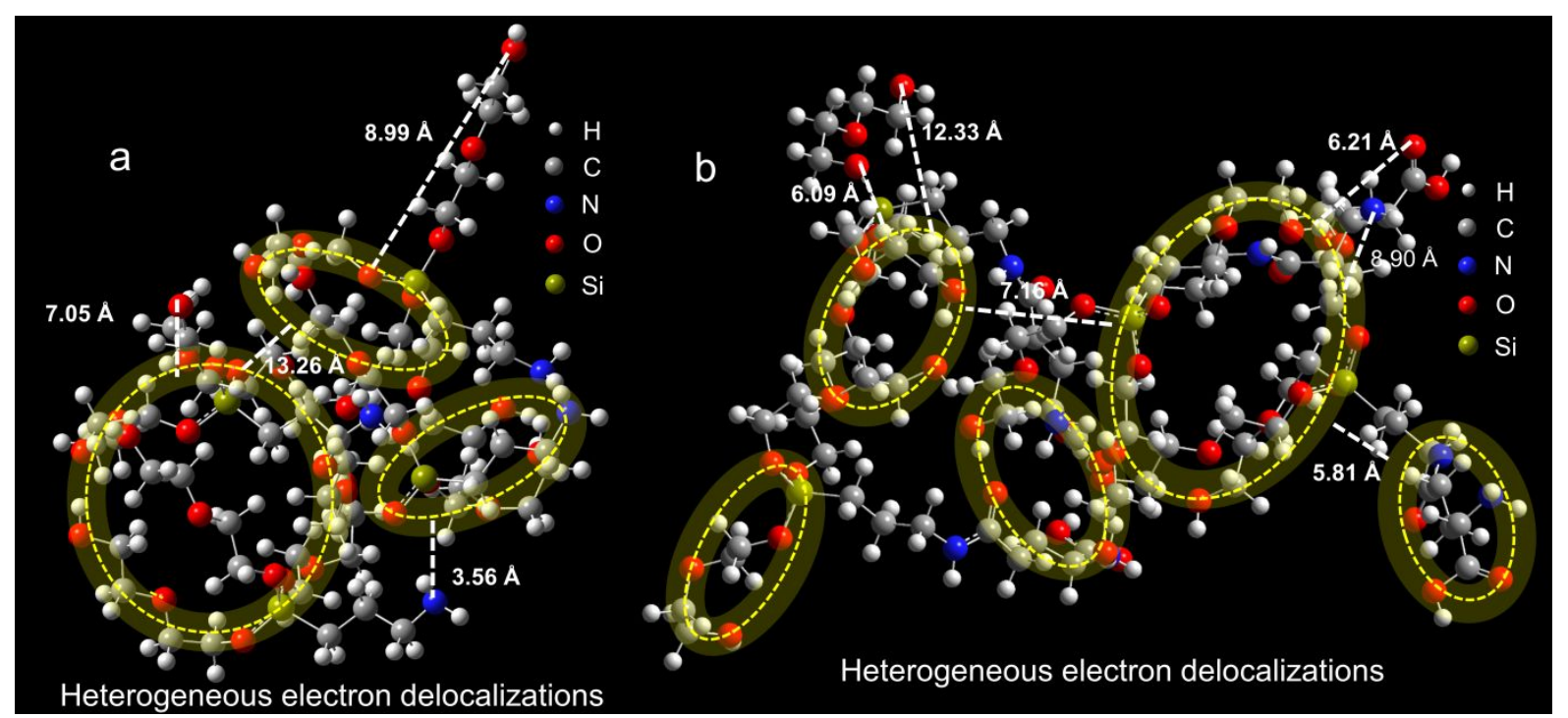

Figure S28. The distance between free functional groups and electron delocalizations, and distance between relatively small electron delocalizations and relatively large electron delocalizations: HBPSi (a) and HBPSi-GA (b). 
a

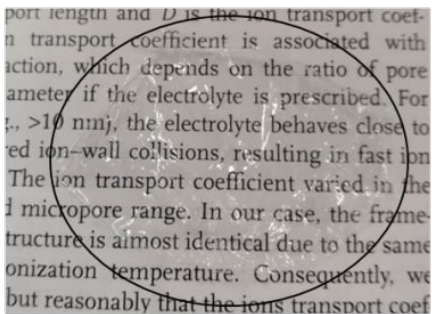

Day light

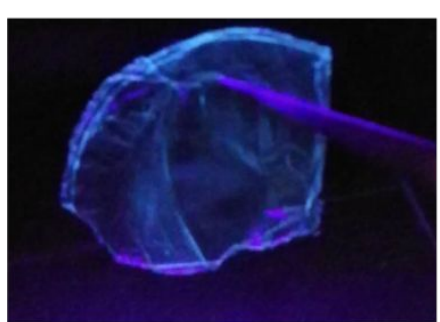

$365 \mathrm{~nm}$

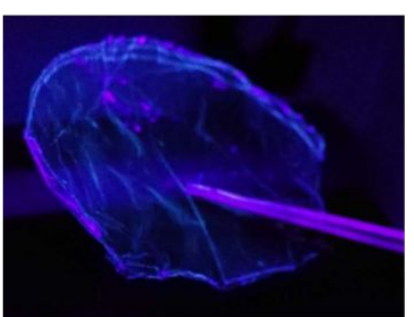

$254 \mathrm{~nm}$
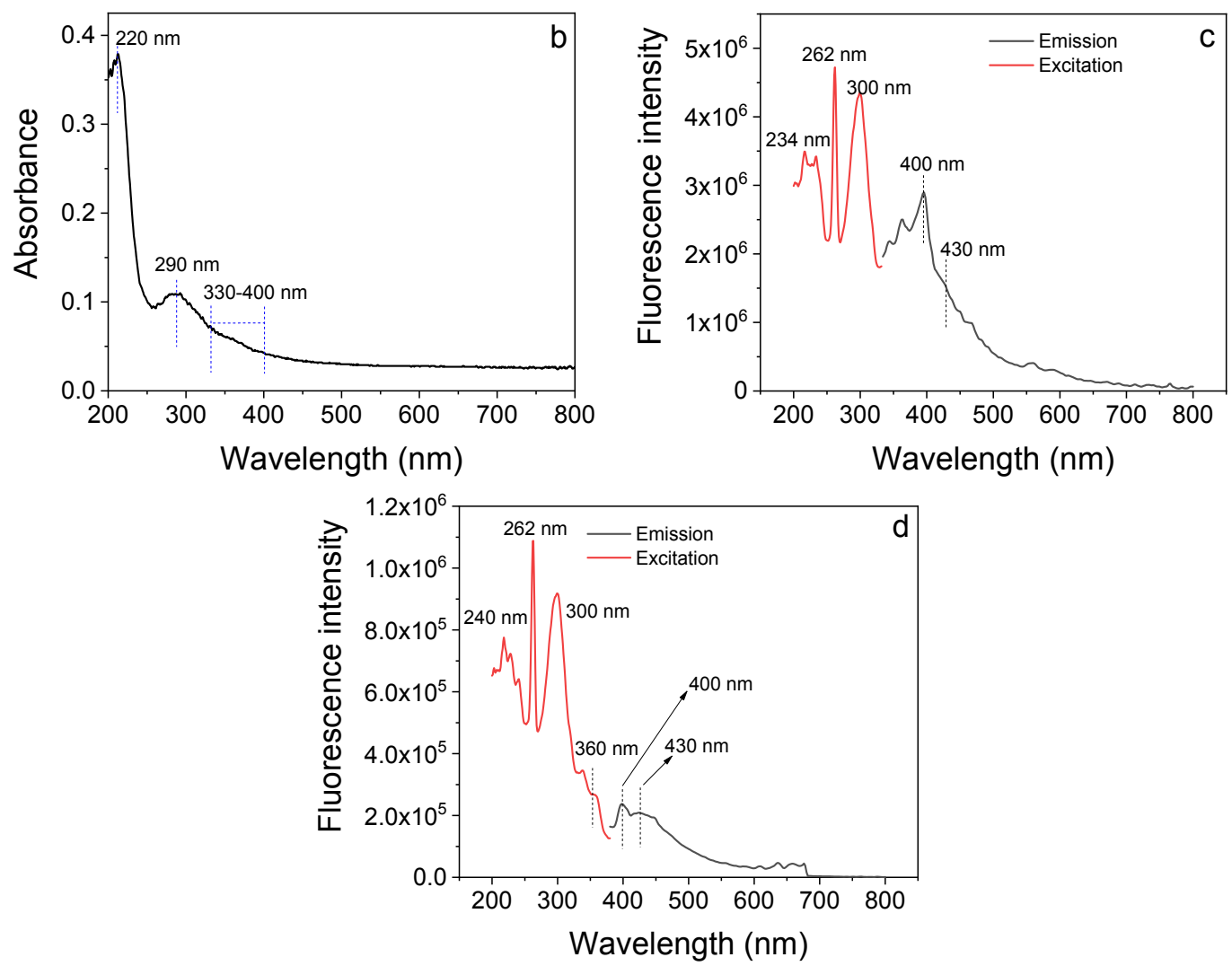

Figure S29. Digital pictures of thin film of HBPSi-GA3 under day light (a), $365 \mathrm{~nm}$ UV light (b) and $253 \mathrm{~nm}$ UV light. UV-vis absorbance spectrum of thin film of HBPSi-GA3 (b). Fluorescence spectra of thin film of HBPSi-GA3: emission spectrum obtained under excitation of $240 \mathrm{~nm}$ and excitation spectrum obtained under emission at $400 \mathrm{~nm}$ (c); emission spectrum obtained under excitation of $360 \mathrm{~nm}$ and excitation spectrum obtained under emission at 430 $\mathrm{nm}(\mathrm{d})$.

$0.01 \mathrm{~g}$ HBPSi-GA3 and $0.05 \mathrm{~g}$ poly(vinyl alcohol) (PVA) was dissolved in $5 \mathrm{mg} \mathrm{mL}-1$ distilled water, was dissolved in $10 \mathrm{mg} \mathrm{mL}^{-1}$ distilled water. Then, these two kinds of solution were dropped on a clean petri dish (diameter is $6 \mathrm{~cm}$ ), thereafter, the petri dish was placed into an oven at $100{ }^{\circ} \mathrm{C}$ for $2 \mathrm{~h}$. Finally, the resulting film was peeled off from the petri dish. UV-vis 
absorbance spectrum of thin film was obtained on a Hitachi U4100 UV Spectrometer. Fluorescence spectra of the thin film were recorded on a steady/transient-state fluorescence spectrometer (FLS980, Edinburgh Instruments). As shown in Figure 29a, the thin film is colorless and transparent, and blue light is observed under 254 and $365 \mathrm{~nm}$ UV light. In the absorbance spectrum of thin film, three peaks at 220, 290 and 330-400 $\mathrm{nm}$ are observed (Figure S29b). The fluorescence spectra of thin film were also obtained. In Figure S29c, there are mainly two peaks at 400 and $430 \mathrm{~nm}$ in the emission spectrum of thin film under excitation of $240 \mathrm{~nm}$, moreover, three peaks at 234, 262 and $300 \mathrm{~nm}$ are observed in the excitation spectra of thin film. After excited by $360 \mathrm{~nm}$ UV light, two emission peaks at 400 and $430 \mathrm{~nm}$ are observed. Four excitation peaks at 240, 262, 300 and $360 \mathrm{~nm}$ are observed in the excitation spectrum of thin film.

\section{REFERENCES}

(1)Feng, Y.; Yan, H.; Ding, F.; Bai, T.; Nie, Y.; Zhao, Y.; Feng, W.; Tang, B. Z. Multiringinduced multicolour emission: Hyperbranched polysiloxane with silicon bridge for data encryption. Mater. Chem. Front. 2020, 4, 1375-1382.

(2)Du, Y.; Bai, T.; Yan, H.; Zhao, Y.; Li, W. A simple and convenient route to synthesize novel hyperbranched poly(amine ester) with multicolored fluorescence. Polymer 2019, 185, 121771.

(3)Luyao; Yuan; Hongxia; Yan; Lihua; Bai; Tian; Zhao; Lianlian; Wang Unprecedented Multicolor Photoluminescence from Hyperbranched Poly(amino ester)s. Macromol Rapid Comm 2018, 40, 1800658.

(4)Zhang, H.; Zhao, Z.; McGonigal, P. R.; Ye, R.; Liu, S.; Lam, J. W. Y.; Kwok, R. T. K.; Yuan, W. Z.; Xie, J.; Rogach, A. L.; Tang, B. Z. Clusterization-triggered emission: Uncommon luminescence from common materials. Mater. Today 2020, 32, 275-292.

(5)Niu, S.; Yan, H.; Li, S.; Xu, P.; Zhi, X.; Li, T. Bright blue photoluminescence emitted from the novel hyperbranched Polysiloxane-Containing unconventional chromogens. Macromol. Chem. Phys. 2016, 217, 1185-1190. 
(6)Feng, Y.; Bai, T.; Yan, H.; Ding, F.; Bai, L.; Feng, W. High fluorescence quantum yield based on the Through-Space conjugation of hyperbranched polysiloxane. Macromolecules 2019, 52, 3075-3082.

(7)Bai, L.; Yan, H.; Bai, T.; Feng, Y.; Zhao, Y.; Ji, Y.; Feng, W.; Lu, T.; Nie, Y. High fluorescent hyperbranched polysiloxane containing $\beta$-Cyclodextrin for cell imaging and drug delivery. Biomacromolecules 2019, 20, 4230-4240.

(8)Bai, L.; Yan, H.; Wang, L.; Bai, T.; Yuan, L.; Zhao, Y.; Feng, W. Supramolecular hyperbranched poly(amino ester)s with homogeneous electron delocalization for multi-stimuli-responsive fluorescence. Macromol. Mater. Eng. 2020, 305, 2000126.

(9) Sun, M.; Song, P. Alicyclic tertiary amine based hyperbranched polymers with excitationindependent emission: Structure, fluorescence and applications. Polym. Chem. 2019, 10, $2170-$ 2175.

(10)Lu, H.; Hu, Z.; Feng, S. Nonconventional luminescence enhanced by Silicone-Induced aggregation. Chem Asian J. 2017, 12, 1213-1217. 